\title{
Hydrodynamic analysis of an axial impeller in a non-Newtonian fluid through particle image velocimetry
}

\author{
David Fernandes del Pozo ${ }^{1}$ (1) | Alain Liné ${ }^{2}$ | Kevin M. Van Geem ${ }^{3}$ (ㄱ) | \\ Claude Le Men ${ }^{2}$ | Ingmar Nopens ${ }^{1}$
}

${ }^{1}$ BIOMATH, Department of Data Analysis and Mathematical Modelling, Ghent University, Ghent, Belgium

${ }^{2}$ INSA, INRA, CNRS, TBI, University of

Toulouse, Toulouse, France

${ }^{3}$ Laboratory for Chemical Technology, Ghent University, Ghent, Belgium

\section{Correspondence}

David Fernandes del Pozo, BIOMATH,

Department of Data Analysis and

Mathematical Modelling, Ghent University, Coupure Links 653, B-9000 Ghent, Belgium.

Email: david.fernandesdelpozo@ugent.be

Funding information

GOA Project, Grant/Award Number: BOF16/ GOA/004

\begin{abstract}
The rheology of non-Newtonian fluids in agitated vessels is complex making equipment sizing more an art than a science. To increase our understanding and to resolve the data gap for computational fluid dynamics validation, we present a detailed particle image velocimetry study of the hydrodynamics of Carbopol encountered in a $70 \mathrm{~L}$ mechanically mixed (A310) tank at three different rotational speeds $(100,250$, $500 \mathrm{rpm}$ ). Bulk flow visualizations show that the flow field below the impeller is highly influenced by the rheological behavior of the fluid. Moreover, an analysis of the shear rate and viscosity revealed important spatial heterogeneities. An estimation of the Reynolds number classified the rotational speeds as the onset of the transitional regime (100), in the transitional regime (250) and turbulent conditions (500 rpm). This data set consists of local mean and fluctuating velocities at different locations below the impeller, which are available for validation and further study.
\end{abstract}

\section{KEYWORDS}

Carbopol, mechanical mixing, particle image velocimetry, proper orthogonal decomposition, shear rate

\section{1 | INTRODUCTION}

During the past decades, the study of hydrodynamics in mechanical stirrers has become more important since mixing is a common unit operation in industry. The common "perfectly mixed" assumption is valid when there is certainty that the flow is fully turbulent, and the timescales of the process are higher than the hydrodynamic ones. However, this is rarely the case in industry where neither the hydrodynamics nor the rheology are homogeneous; consequently, in such cases, neither the fluid regime nor the hydrodynamics timescales are known with certainty. Non-Newtonian fluids displaying complex rheology are present in important key sectors of industry such as biotech (e.g., fermentation broths), and wastewater treatments (e.g., anaerobic digesters $[A D])$. The complexity in describing such systems might be translated into oversizing mixing equipment and the application of conservative mixing operations (e.g., applying safety factors and operating at high revolutions per minute [rpm]). Although a large body of literature has been devoted to the study of fast mixing of Newtonian fluids such as water, little work has been done to understand the mixing processes of non-Newtonian fluids and their scalability. The latter have their material functions due to the interactions between its structural units. This makes the study on non-Newtonian fluids more challenging and the results typically case dependent. Evaluating the mixing efficiency for non-Newtonian fluids is not a trivial task. It requires a deep understanding of how these fluids dissipate energy and the link with the local fluid properties. In this respect, advanced modeling techniques such as computational fluid dynamics (CFD) enable the possibility of troubleshooting and virtual piloting once these mechanisms are properly understood. These models must first be validated and applied once their accuracy has been thoroughly evaluated by comparison with experimental data with representative fluids. In this respect, several high-quality data sets devoted to study the local hydrodynamics of radially producing flow impellers (e.g., Rushton turbines), but not for axially producing flow impellers. 
These are, for some applications, more interesting because they tend to maximize the flow advected while minimizing their energy consumption and shear impact. ${ }^{1}$

Axial flow impellers are usually employed to promote global circulation within the tank while producing moderate shears at the vicinity of the impeller compared to other types of impellers. As described in A310 mixer's patent, ${ }^{2}$ the shape of the blades is designed to reduce drag by maximizing discharge axial flow before blade flow separation. Thus, hydrofoil types of impellers tend to produce a much more streamlined flow due to the complex hydrodynamic shape of its blades compared to pitch-blade impellers. This feature enables the use of axial impellers to blend liquids and solids, in low Reynolds number applications, and to mix low to medium shear-thinning viscous fluids. ${ }^{1,3}$ Most of the work done with hydrofoil impellers tends to experimentally determine global quantities and local mean velocity profiles in water using different measurement techniques such as laser Doppler anemometry and particle image velocimetry (PIV). ${ }^{2,4-11}$ Note that some work has been devoted to study the $\mathrm{A} 310$ mixing capability for other non-Newtonian fluids, ${ }^{12,13}$ or to study the mixing of Carbopol with other impellers. ${ }^{14,15}$ Since shear rate is usually a controlling factor in processes such as flocculation or precipitation, numerous studies have focused on the determination of local shear rate and its relation with process performance in water. ${ }^{16-20}$ However, very few studies ${ }^{8,21,22}$ have made an in-depth turbulence analysis of the A310 due to the difficulty of measuring the required turbulence terms. These studies confirmed that in water the $\mathrm{A} 310$ significantly dissipates energy in the impeller's swept volume ( $\approx 40 \%$ in Reference 8 and $\approx 30 \%$ calculated with $\mathrm{CFD}^{23}$ ). The dissipation rate of kinetic energy is also an important parameter related to process performance and turbulence analysis. However, the estimation of the dissipation rate in mechanical stirrers turns out to be complex and it usually involves high-resolution measurements. Some authors have attempted its determination using different approaches (e.g., using macroscale variables or a balance of total kinetic energy from experimental data)..$^{6,8,24}$ Compared to Rushton turbines, within the region of the discharge flow in water, its estimation is one order of magnitude lower and has a different dissipation profile than $\mathrm{A} 310 .^{25-27}$

With stricter environmental regulations, wastewater treatment plants (WWTPs) are under constant pressure to minimize their energy consumption while providing an adequate mixing level. In this respect, $A D$ are one of the most challenging processes since they deal with highly viscous and complex solid-liquid slurries. It is recognized as one of the WWTP processes that would most benefit from a deeper understanding of its mixing process at large volumes. ${ }^{28}$ The lack of hydrodynamic experiments combined with little validation studies using CFD models for AD mechanical mixers might explain the large uncertainties associated with these models. ${ }^{29,30}$ As for anaerobic digestion, even fewer work has been made to obtain local hydrodynamic data for mechanical mixers. The main reason is that $A D$ sludge is highly opaque and cannot permit the use of conventional flow visualization techniques. For biogas mixing and mechanical stirring, some studies used nonintrusive flow visualization techniques such as computer automated radioactive particle tracking, ${ }^{31,32}$ and Positron emission particle tracking. ${ }^{33}$
Therefore, the objectives of the current article are twofold: (a) analyze the hydrodynamics at different flow regimes produced by an axial impeller (A310) in a single-phase non-Newtonian medium (Carbopol) and (b) provide a highly accurate data set to evaluate the strengths and weaknesses of CFD models. The Lightning A310 is selected in this work to be a good representative of an axial hydrofoil impeller employed in industry, representative for an $A D$ reactor.

\section{MATERIALS AND METHODS}

\section{1 | Fluid}

Since biological sludges are highly opaque, the use of clear model fluids is becoming more popular since they can then be analyzed with flow visualization techniques. ${ }^{34,35}$ Carbopol 980 (0.06 wt\%, Sigma Aldrich) is mixed with high purity water and carefully neutralized with a drop-by-drop addition of a base solution $(\mathrm{NaOH})$, creating a suitable transparent fluid model that will rheologically mimic the digested sludge. $^{36}$ The concentration of Carbopol is adjusted to behave as similar as possible to a collected sample of roughly 3-4\% total suspended solids of digested sludge. Thus, Carbopol (as well as anaerobically digested sludge) is modeled with the three-parameter model Herschel-Bulkley (HB; Equation (1)), which can capture the sludge shear thinning behavior and the apparent yield stress. ${ }^{37}$

$$
\tau=\tau_{0}+K \dot{\gamma}^{n} ; \mu(\dot{\gamma})=\frac{\tau_{0}}{\dot{\gamma}}+K \dot{\gamma}^{n-1}
$$

where $\tau$ is the shear stress, $\tau_{0}$ is the apparent yield stress, $K$ and $n$ are the consistency and power law index, and $\dot{\gamma}$ is the magnitude of the shear rate.

The Carbopol flow curve (Figure 1) is obtained from a Thermo Haake rheometer with a smooth stainless-steel Cone and Plate $\left(2^{\circ}\right)$ geometry in a shear-rate controlled mode. A local optimizer is used for calibration of the HB model (scipy.curve_fit) while fixing the apparent yield stress $\left(\tau_{0}=0.3 ;{ }^{38}\right)$ for three independent samples taken in a period time of 10 days during the experiments. As reported by some authors, ${ }^{38-40}$ the existence of wall slip restricts us to calibrate the model for the full range of shear rates, so the model is strictly valid for the calibrated range $\dot{\gamma}=[1-100] \mathrm{s}^{-1}$. Although not measured by us, it is assumed that at this low concentration, $\rho \approx 1,000 \mathrm{~kg} / \mathrm{m}^{3}$. ${ }^{40}$

\section{2 | Mixing tank}

The tank used in this study consists of a standard cylindrical vessel $(V=71.6 \mathrm{~L})$ equipped with four equally spaced baffles (width $B=0.045 \mathrm{~m}=\mathrm{T} / 10$ ). The vessel is made of poly(methyl methacrylate) and had a diameter and a liquid height of $T=H=0.45 \mathrm{~m}$. The cylindrical tank has a flat bottom and is placed in a cubic tank filled with water to minimize optical refraction. The impeller used in this study is 

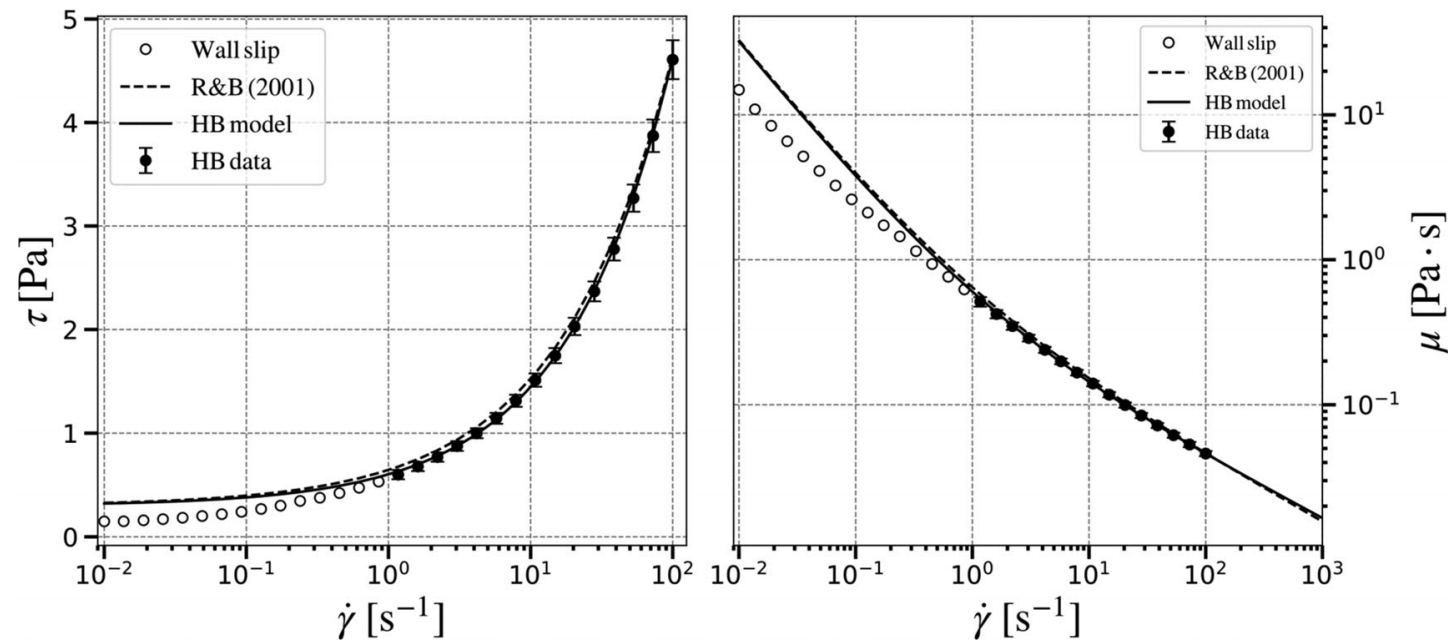

FIGURE 1 Rheological profiles of Carbopol with a calibrated Herschel-Bulkley (HB) model $\left(\tau_{0}=0.300 ; K=0.303 ; n=0.577\right)$ and HB parameters from Reference $38\left(\tau_{0}=0.300 ; K=0.345 ; n=0.55\right)$. The uncertainty measurement is shown as standard deviation (SD) of each point and visualized using error bars. Note that the $y$-left axis of the left subplot is not in logarithmic scale to better visualize the apparent yield stress

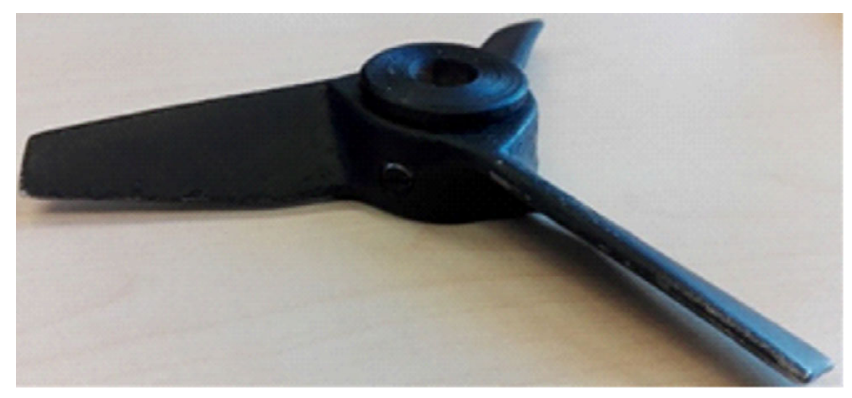

FIGURE 2 A310 impeller used in this study coated with black paint to minimize laser refraction [Color figure can be viewed at wileyonlinelibrary.com]

a standard A310 hydrofoil impeller with $D=T / 3=0.15 \mathrm{~m}$ (Figure 2), equal to the impeller clearance $(C)$ and mounted at the center.

\section{3 | PIV methodology}

In this work, a set of different experiments have been carried out to analyze the main flow features below the impeller and at different impeller revolutions (Figure 3 and Tables S1 and S2 in Supplementary Materials). The procedure followed was to fix the PIV plane at known spatial coordinates and acquire the PIV data for all rotational speeds. Depending on the location of the camera with respect to the laser sheet, different planes were obtained inside the vessel. Since the acquisition of data is done with two-dimensional (2D) fields, the PIV software provides two sets of the possible three instantaneous components of the velocity fields $\left(U_{X}, U_{Y}, U_{Z}\right)$, in a Cartesian frame $(X, Y, Z)$. Later, a statistical post-processing is applied to the PIV fields to obtain the mean velocity components and other statistically averaged quantities. Since only two components of the velocity field are captured by the PIV method, additional PIV fields are obtained when intersecting two PIV perpendicular planes to obtain the three-time averaged velocity components at the intersection. Additionally, a third set of PIV fields are acquired to obtain the nine components of the Reynolds stress tensor for a full description of the hydrodynamics when three perpendicular PIV fields intersect each other.

In order to gather these data, three different PIV measurement planes were considered:

1. $Y Z(X=0 \mathrm{~mm})$ : This plane is used as the reference for the threedimensional (3D) intersection with respect to other PIV planes, being the bottom center part of the impeller the origin $(0,0,0)$ of the Cartesian coordinate frame. This plane is a bisector plane relative to two baffles. This plane is also used to check for axisymmetry when rotated $90^{\circ}$ named $X Z(Y=0 \mathrm{~mm})$.

2. $Y Z(X=30,60,90 \mathrm{~mm})$ : Three different PIV planes are obtained by displacing the laser sheet $30 \mathrm{~mm}$ in the radial $X$-direction of the Cartesian frame.

3. $X Y(Z=1,26,51,76,101 \mathrm{~mm})$ : Five different PIV planes are obtained by displacing the laser sheet $25 \mathrm{~mm}$ in the axial downward Z-direction. The first plane is located $1 \mathrm{~mm}$ below the impeller.

Although not every plane will be used in this work, the data set is openly available so that it is further possible to describe the hydrodynamics below the impeller at 16 different locations by intersecting the different PIV planes.

\section{$3 \mid$ RESULTS}

\subsection{Mean velocity flow, $Y Z(X=0 \mathrm{~mm})$}

In Figure 4, the mean velocity magnitude and vectors are plotted for the different rpms. It can be observed that at a low rpm of 100 , the 

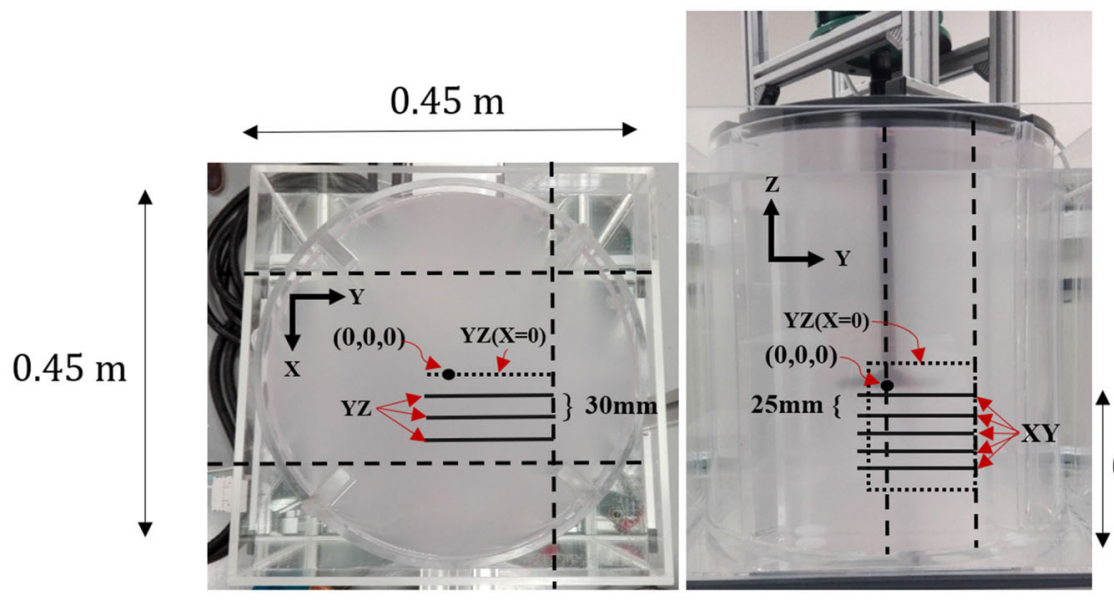

$0.15 \mathrm{~m}$
FIGURE 3 Dimensions of the particle image velocimetry (PIV) setup and location of the laser sheet ( $Y Z$ and $X Y$ ) with respect to the impeller. The dashed lines (--) indicate the maximum depth of field imposed by the baffles and the axis of symmetry and the dot $(0,0,0)$ indicates the origin. The fine dashed line (....) on the left figure indicates an approximate size of the $X Z$ field. The impeller rotates in the clockwise direction [Color figure can be viewed at wileyonlinelibrary.com]

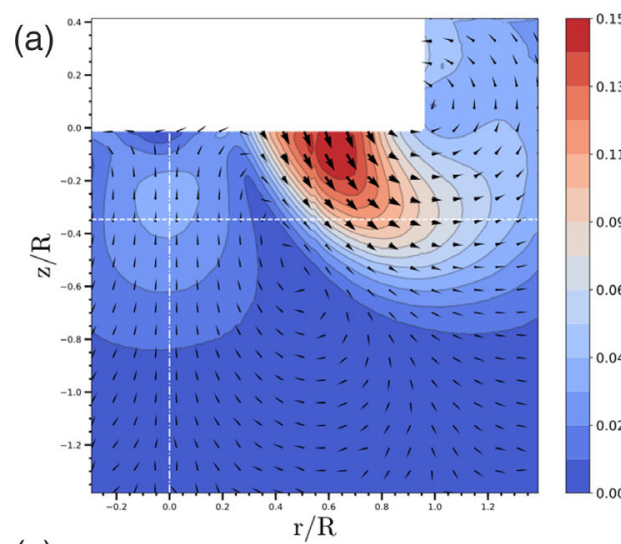

(c)
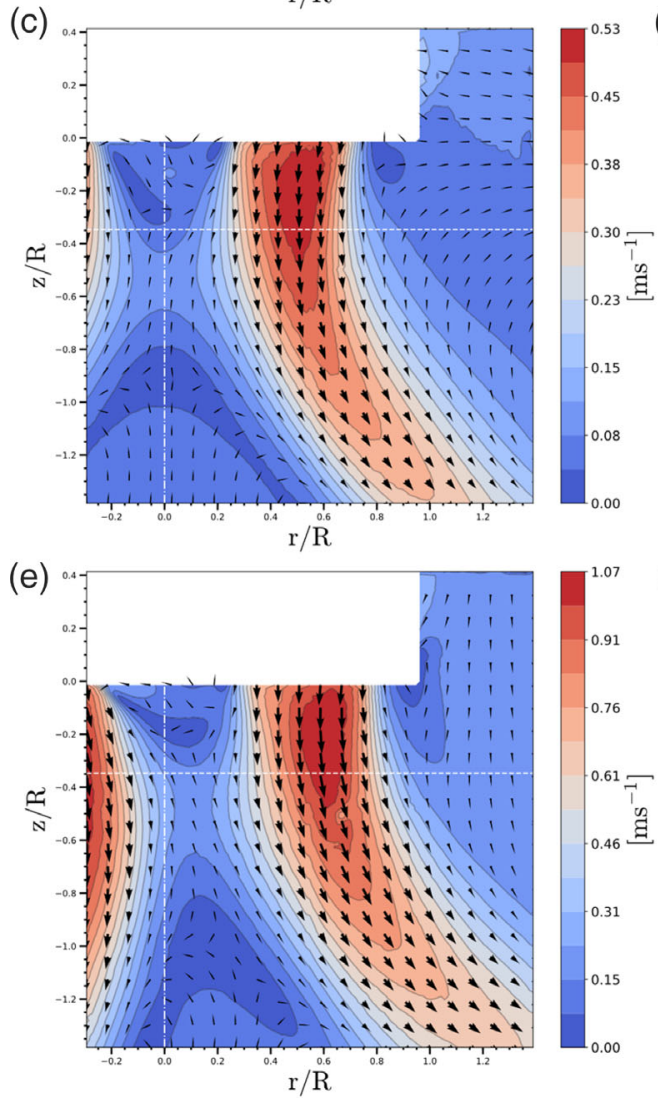

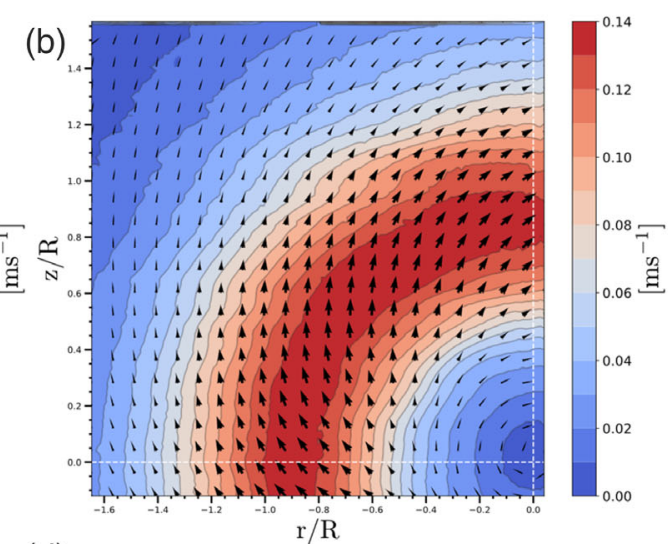

(d)

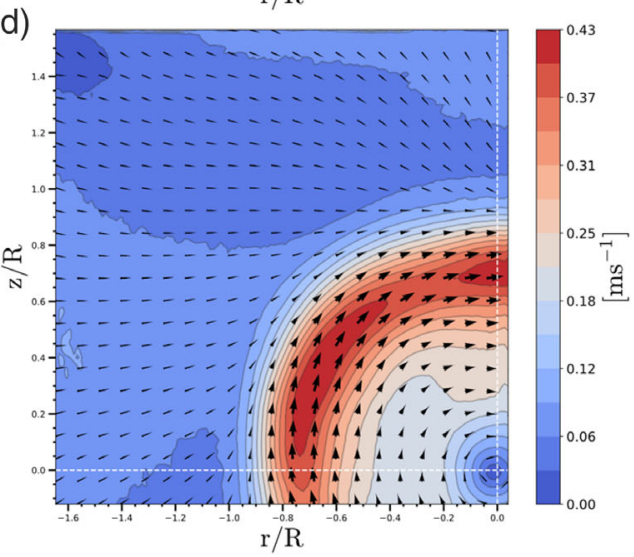

(f)

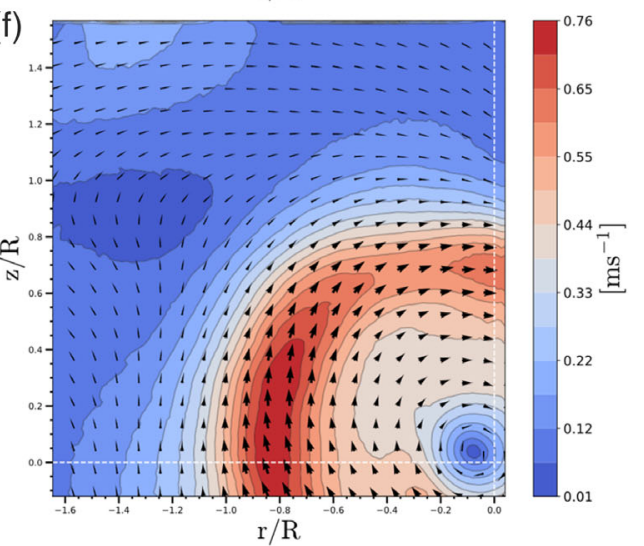

FIGURE 4 Mean velocity

contour and vector plots of plane $Y Z(x=0 \mathrm{~mm})(a, c, e)$, and $X Z$ $(z=26 \mathrm{~mm})(b, d, e)$ for $100(a, b)$; 250 (c,d); and 500 rpm (e,f). The white "- . -" lines indicate the impeller rotation axis, "- -" lines indicate the intersection line between planes. A white mask has been applied in the vicinity of the impeller and shaft for visualization purposes. Each arrow starts from the grid point represented with its arrowhead proportional to its magnitude. The radial and height profiles are divided by the blade tip radius $(R=0.075 \mathrm{~m}$ ) [Color figure can be viewed at wileyonlinelibrary.com] 
impeller does not transmit sufficient momentum to the viscous fluid and a cavern appears promoted by a weak downward axial-radial jet. This structure appears to be as a lobe, a distinctive feature of chaotic laminar mixing. ${ }^{41}$ As the rpm is increased, there is a continuous development of a downward jet that is able to overcome the low rpm highly viscous region. It is also observed that the main circulation loop increases in size with respect to a second circulation loop located at the bottom of the impeller and near the impeller's rotation axis. At $100 \mathrm{rpm}$, the flow seems axisymmetrical with respect to the impeller's rotational axis: the cavern size is relatively small and the baffles (along the tank wall) do not affect the flow close to the impeller. However, at $500 \mathrm{rpm}$, the flow is observed to be no longer axisymmetric. One possible explanation is that at such high rpm, the flow fields are influenced by the interactions of the flow with respect to the baffles.

\subsection{Root mean square of velocity fluctuations, $\mathrm{YZ}(\mathrm{X}=0 \mathrm{~mm})$}

Next, the root mean square (RMS) of the fluctuating velocity component (Equation (2)) is analyzed in Figure 5.

$$
\frac{\sqrt{{U_{\text {fluc }}^{-}}^{2}}}{U_{\text {tip }}}=\frac{\sqrt{U_{\text {fluc, }, Y^{2}+U_{\text {fluc }, Z^{2}}}}}{U_{\text {tip }}}
$$

Figure 5 displays the percentage of the normalized RMS as a function of the rotational speed. Although intense fluctuations (>10\%) are achieved near the impeller, only high fluctuations (5-7\% and $8-12 \%)$ are achieved inside the impellers jet for 250 and $500 \mathrm{rpm}$. However, fluctuations decay very quickly and achieve bulk values around $<1-3 \%$ for all rotational speeds. These fluctuations include both periodic ones (induced by the impeller blades rotation) and random ones. Their distinction will be addressed later.

\section{3 $\quad$ Mean velocity component profiles}

The profiles of the mean radial $(r)$, axial $(z)$, and tangential $(\theta)$ velocities normalized with the impellers tip velocity are plotted in Figure 6. Additionally, the $90^{\circ}$ orthogonal components in the XY plane of the radial-tangential velocities are also plotted to check for axisymmetry around the axis of rotation.

The normalized components in Figure 6 show that the tangential and axial components are the highest for the three rotational speeds, with the radial component only being important at $100 \mathrm{rpm}$. The comparison of all radial profiles at two different depths $(Z=-0.35 ;-0.68 z)$ $R$ ) reveals that viscous forces tend to decrease and smear out the three velocity components even at such short distances from the impeller. Furthermore, the comparison of the axisymmetric components $(r-\theta)$ of the XY plane confirms the loss of axisymmetry around the centre of rotation for the $500 \mathrm{rpm}$ case (Figure $6 \mathrm{c}, \mathrm{f}$ ). The good overlap between radial components from two different planes $(Y Z(X=0 \mathrm{~mm})$ and $X Y(Z=26 \mathrm{~mm})$ reassures the spatial intersection location was correct, as it can also be seen in Figure S2 in Supplementary Materials).

\section{4 | Proper orthogonal decomposition}

Figure 5 revealed that the intensity of the fluctuations is high near the impeller while decaying quickly away from the impeller for all rotational speeds. Since the origin of these fluctuations remain unclear, the following section will attempt to determine if the origin of these fluctuations is mainly related to the periodic blade passage, or due to random turbulence. Traditionally, conditional averaging (phase-average) is applied during PIV processing to identify possible periodic structures induced by the rotation of the impeller blades. However, this technique is time-consuming, and a lot of planes have to be studied to reconstruct the periodically oscillating fields (as a function the plane angle with respect to the blade). Alternatively, a technique named snapshot proper orthogonal decomposition (POD) is applied (a)

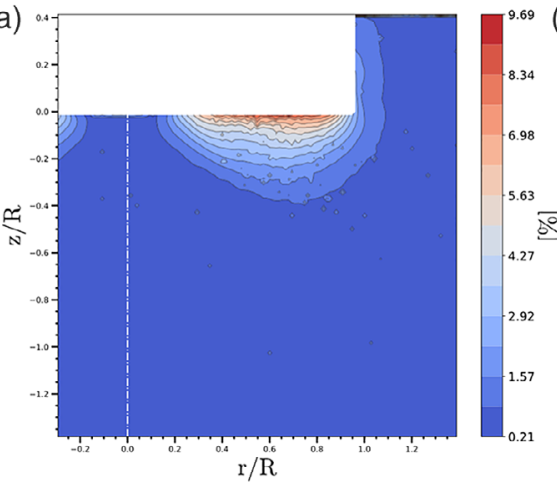

(b)

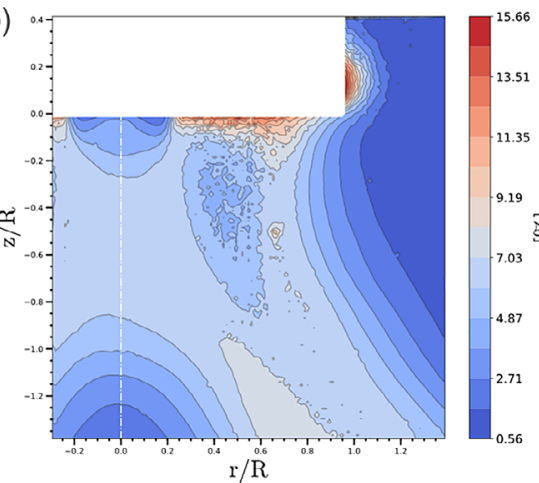

(c)

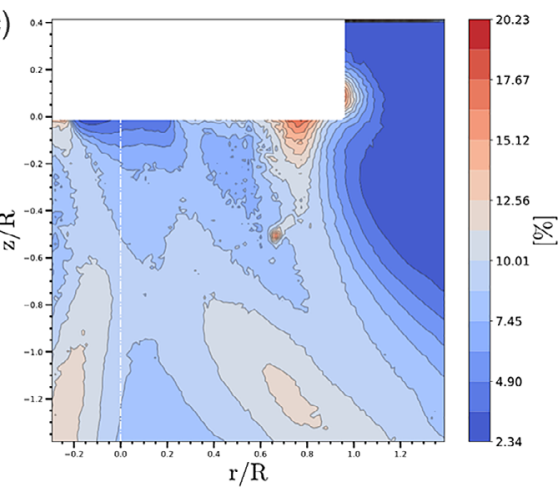

FIGURE 5 Percentage of the normalized RMS $\left(\sqrt{{U_{\text {fluc }}^{-}}^{2}} / U_{\text {tip }}\right)$ contour plot of the fluctuant velocity for (a) 100, (b) 250, and (c) 500 rpm. RMS data have been nondimensionalized by dividing by the tip velocity [Color figure can be viewed at wileyonlinelibrary.com] 

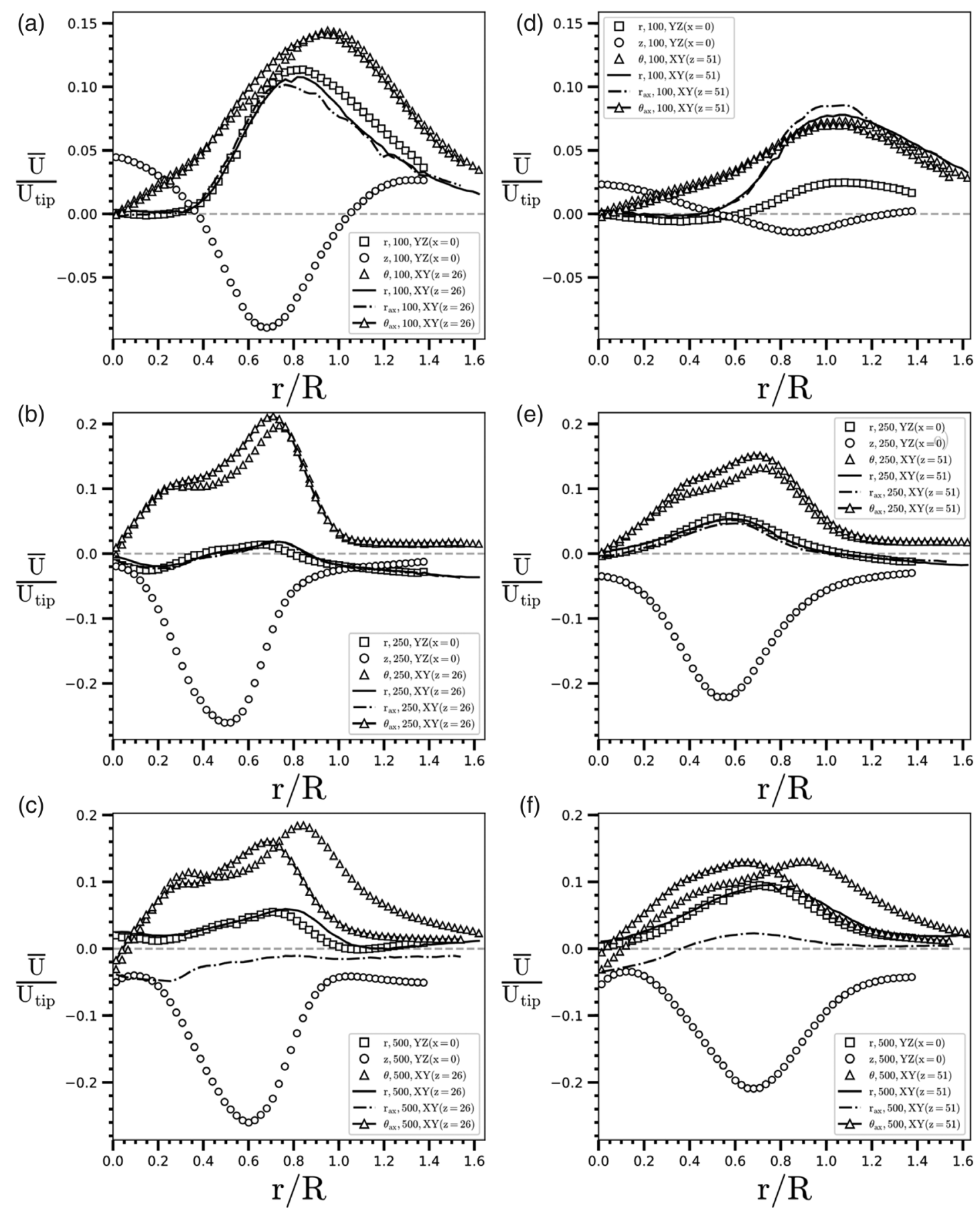

FIGURE 6 Normalized mean radial $(r)$, axial $(z)$, and tangential $(\theta)$ velocity component profiles at $26(Z=-0.35 z / R$; a-c) and $51 \mathrm{~mm}(Z=$ $-0.68 z / R ; d-f$ ) below the impeller for 100 (a,d); 250 (b,e); and 500 rpm (c,f) from different particle image velocimetry (PIV) sets of experiments. Axisymmetric components $\left(90^{\circ}\right)$ are labeled as ax

since it is able to identify periodic structures using nontime resolved PIV data ${ }^{42,43}$ (see Supplementary Materials for more information).

\subsection{1 | Eigenvalue spectrum}

The presence of organized motion can be thought of hydrodynamic structures, and they could be distinguished from random turbulent structures since they are periodic in time, have associated frequency and wavelength. Even if POD is applied, due to the highly complex nature of the 3D flow, the distinction between organized motion and turbulence is not a trivial task especially if only $2 \mathrm{D}$ components are studied. One of the advantages of the POD method, is that it is possible to propose quantitative arguments for this separation based on an in-depth analysis of the obtained modes (eigenvectors and timedependent coefficients) and their associated eigenvalues. Organized motion is energetic, and its hydrodynamic structures have a lower associated frequency compared to random turbulence (which have 
higher frequencies associated with the eddy energy cascade theory). For this reason, an analysis on the eigenvalue spectrum is carried out by analyzing the percentage variation of the kinetic energy associated with each mode (represented in terms of normalized eigenvalues, Equation (3)) as shown in Figure 7:

$$
\lambda_{I}^{*}=\frac{\lambda_{I}}{\sum_{i=1}^{M} \lambda_{i}}
$$

As observed in Figure 7, the first mode is the most energetic one and it is associated with the mean flow. Oudheusden et al. ${ }^{44}$ showed that organized motion can be identified by pairs of modes with similar energy and with clear separation between consecutive pair of modes. Table 1 contains a summary of the kinetic energies associated with each mode as a function of the rpm and data set. Figure 7 reveals that clear organized structures may be present for $100 \mathrm{rpm}$ with Modes 2-3 (and 4-5 for plane YZ $(X=0)$ ). The higher the rpm, the more difficult it is to distinguish organized motion since they are not easily identified anymore. For $250 \mathrm{rpm} \mathrm{XY}$, it seems that at least 10 modes are necessary until a change of slope with Modes 2-3 containing 7.5\% KE for the $X Z$ plane. Additionally, ${ }^{45}$ argued that the eigenvalues $(\lambda)$ are a generalization of the energy density spectrum and they proposed the relation $\lambda^{\prime} \propto I^{-11 / 9}$ to analyze which range of modes dissipate energy isotropically (known as the inertial subrange). This trend seems to be obeyed in an intermediate range of modes for the $500 \mathrm{rpm}$ case, indicating that for this case the flow can be considered almost turbulent (124/150 modes are necessary to obtain 95\%KE). For $250 \mathrm{rpm}$, an intermediate range of modes seems to only be displaying this trend, indicating that the flow may achieve turbulence at the impeller discharge.

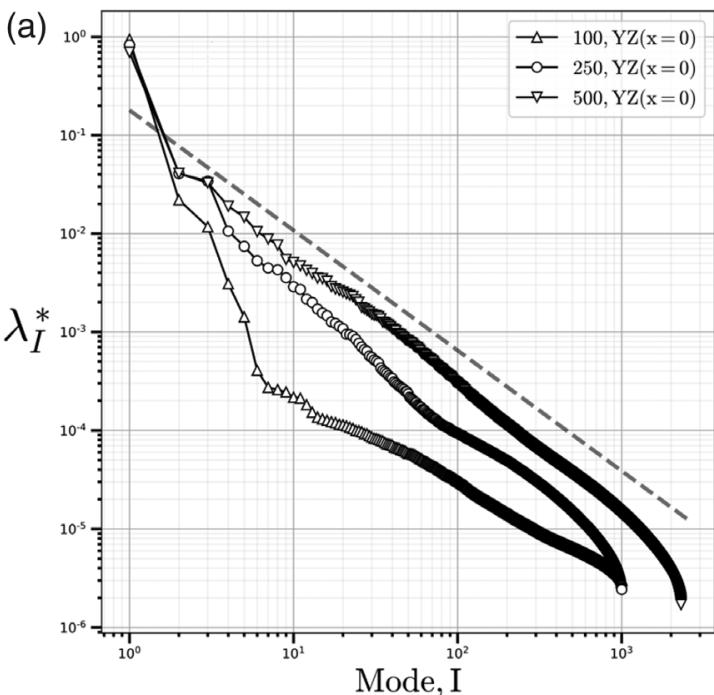

\subsection{Local averaged total shear rate}

The local distributions of the $2 \mathrm{D}$ reconstruction of averaged total shear rate $\left(\dot{\gamma}_{\text {rms }}^{-}\right.$, Supplementary Materials) for rotational speeds 100, 250, and $500 \mathrm{rpm}$ are plotted in Figure 8.

In terms of spatial distribution, the mean shear rate is high around the impeller at all rotational speeds because this region achieves the largest velocity gradients. At high impeller speeds, the difference between the maximum and bulk shear rate increases with maximum values encountered near the tip of the impeller $\left(\bar{\gamma}_{\max } \sim 50,260,600 \mathrm{~s}^{-1}\right)$. Additionally, high shear rates are also found inside the axial-radial jet.

\subsection{Local apparent viscosity}

Since the instantaneous velocity gradients are available, it is worth to compare the calculation of the average viscosity by two different statistical methods with: (a) the correct definition using the averaged instantaneous shear rate (Equation (4)) and (b) using the previously timeaveraged shear rate (Equation (5)). The latter is an approximation often used in Reynolds average Navier-Stokes (RANS) CFD calculations:

$$
\begin{gathered}
\mu \overline{\dot{\gamma}})=\frac{\tau_{0}}{\dot{\gamma}}+K \dot{\gamma}^{n-1} \\
\mu\left(\dot{\gamma}_{\mathrm{rms}}^{-}\right)=\frac{\tau_{0}}{\dot{\gamma}_{\mathrm{rms}}^{-}}+K \dot{\gamma}_{\mathrm{rms}}^{--1}
\end{gathered}
$$

The local distributions of 2D reconstruction of mean viscosity for rotational speeds of 100, 250, and 500 rpm are plotted in Figure 8 when using the calibrated $\mathrm{HB}$ model.

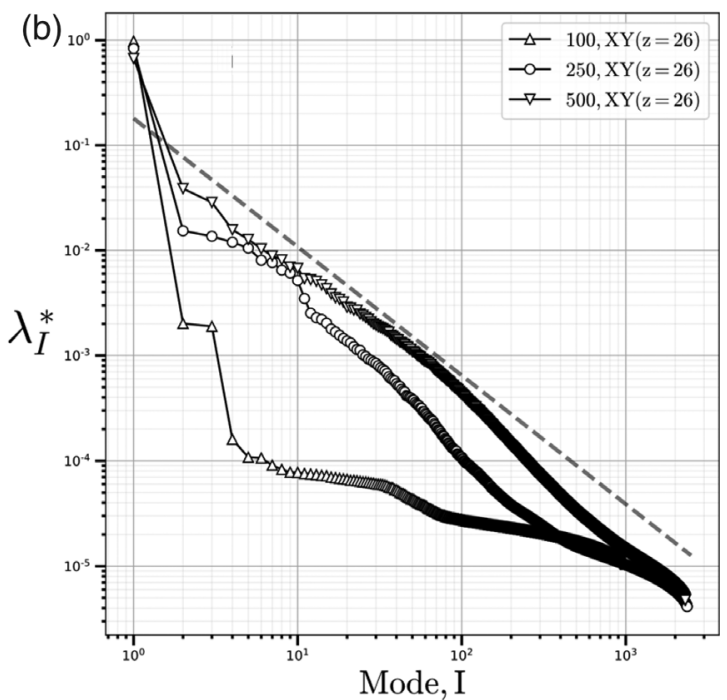

FIGURE 7 Normalized eigenvalues as a function of the POD mode number for (a) $Y Z(X=0 \mathrm{~mm})$ and $(b) X Y(Z=26 \mathrm{~mm})$. The dashed line indicates the $-11 / 9$ slope characteristic of the inertial subrange $\left(I^{-11 / 9}\right)$ 


\begin{tabular}{|c|c|c|c|c|c|c|c|}
\hline \multirow[b]{2}{*}{$N(\mathrm{rpm})$} & \multirow[b]{2}{*}{ Plane } & \multicolumn{4}{|c|}{$\% \mathrm{KE}_{2 \mathrm{D}}$} & \multirow[b]{2}{*}{$I_{>95 \%, \mathrm{KE}}$} & \multirow[b]{2}{*}{$\bar{K}_{\mathrm{TOT}, 2 \mathrm{D}}\left(\mathrm{m}^{2} / \mathrm{s}^{2}\right)$} \\
\hline & & $I=1$ & $I=2-3$ & $I=4-5$ & $I=6-M$ & & \\
\hline 100 & $Y Z(x=0)$ & 94.7 & 3.4 & 0.5 & 1.4 & 2 & 23 \\
\hline 100 & $X Y(z=-26)$ & 97.6 & 0.4 & $\approx 0$ & 2.0 & 1 & 107 \\
\hline 250 & $Y Z(x=0)$ & 83.0 & 7.5 & 1.8 & 7.7 & 13 & 739 \\
\hline 250 & $X Y(z=-26)$ & 83.4 & 2.9 & 2.2 & 11.4 & 31 & 530 \\
\hline 500 & $Y Z(x=0)$ & 70.0 & 7.4 & 3.4 & 19.3 & 124 & 3,866 \\
\hline 500 & $X Y(z=-26)$ & 66.9 & 6.7 & 2.8 & 23.5 & 150 & 2,596 \\
\hline
\end{tabular}

TABLE 1 Plane averaged 2D kinetic energies associated with POD modes as a function of rpm and data set
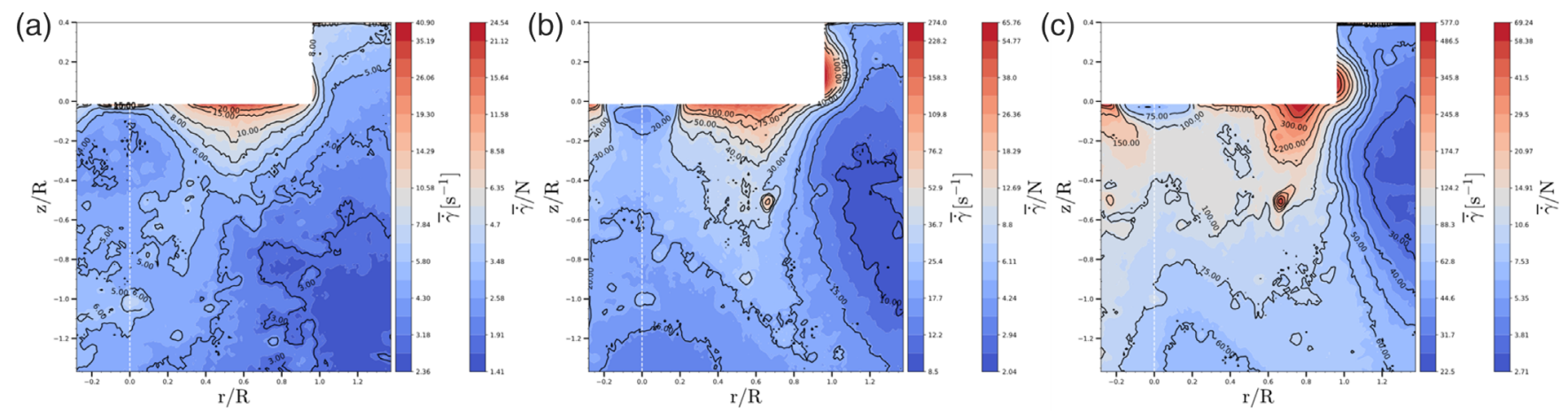

FIGURE 8 Logarithmically spaced contour plots of mean total shear rate $\left(\dot{\gamma}_{\text {rms }}^{-}\right)$for (a) 100, (b) 250, and (c) $500 \mathrm{rpm}$ at plane YZ (X = $\left.0 \mathrm{~mm}\right)$ [Color figure can be viewed at wileyonlinelibrary.com]

The difference between apparent viscosity distribution among different rotational speeds and statistical treatment is shown in Figure 9. At low rotational speeds, the flow confinement around the impeller seems to be in agreement with the presence of a heterogeneous viscosity distribution. When the impeller does not transmit enough energy to the fluid, the fluid flows close to the impeller with less velocity and fluctuations, and hence produces less intense velocity gradients. As soon as the shear rates fall, the viscosity of the fluid greatly increases, and the dissipation of energy is greater. As the rotational speed is increased, lower values of viscosity are obtained with minimum values being at least 10 times greater than the viscosity of water. At $100 \mathrm{rpm}$, a rough estimate of the lowest shear stress achieved in this region $(\tau=\mu(\dot{\gamma}) \cdot \dot{\gamma} \approx 0.4 \cdot 2.3=0.92$ $\mathrm{Pa}$ ) indicates that it is at least three times greater than the apparent yield stress of the fluid (from experimental estimation see Figure 1). This result is of particular value since the flow field can be greatly modified by shear stresses higher than the apparent yield stress of the fluid when working with these types of rheological behavior.

The second observation is related with the difference in magnitude and spatial distribution when using Equation (4) or (5) to calculate local mean viscosity, which can be quite important at lower impeller speeds (Figure 9a,b). It seems that Equation (4) (the one used by RANS simulation approaches) underestimates the apparent viscosity values. One possible explanation might be that lower velocity gradients generate relatively high viscosities, which may weight more in the calculation of the mean, compared to the results of the second statistical treatment. However, the magnitude of the error produced by Equation (4) in CFD calculations remains unclear and should be explored in future studies.

\subsection{Dissipation rate of fluctuant kinetic energy}

The experimental determination of the dissipation rate of kinetic energy is a complex task in mechanical stirrers. Several authors have tried in the past different approaches to obtain an estimation of its value in the vicinity of the impeller as reported in the literature review. Since in this work several velocity gradients are available at multiple planes, an attempt is made to reconstruct the average dissipation rate of kinetic energy using 2D PIV data. The averaged dissipation rate of total kinetic energy is defined $\mathrm{as}^{46}$ :

$$
\begin{gathered}
\varepsilon_{\text {tot }}=\frac{\mu(\dot{\gamma})}{\rho} \dot{\gamma}^{2}=2 \frac{\mu(\dot{\gamma})}{\rho} S: S=\frac{\mu(\dot{\gamma})}{\rho} 2 \sum_{i=1}^{3} \sum_{j=1}^{3} \frac{\partial U_{i}}{\partial x_{j}}\left(\frac{\partial U_{i}}{\partial x_{j}}+\frac{\partial U_{j}}{\partial x_{i}}\right) \\
\varepsilon_{\text {tot }}=\bar{\varepsilon}+\varepsilon_{\text {fluc }}=2 \frac{\mu(\dot{\gamma})}{\rho}\left(\bar{S}: \bar{S}+S_{\text {fluc }}: S_{\text {fluc }}\right)
\end{gathered}
$$

where $\varepsilon_{\text {tot }}, \bar{\varepsilon}$, and $\varepsilon_{\text {fluc }}$ are the dissipation rate of total, mean, and fluctuant kinetic energy, $\rho$ is the fluids density, and $S$ and $S_{\text {fluc }}$ are the instantaneous total and fluctuating shear rate (strain-rate) tensors. In turbulent regime, $S_{\text {fluc }}: S_{\text {fluc }} \gg \bar{S}: \bar{S}$ since the fluctuating time scales are much smaller than the macroscopic time scales, producing larger local velocity gradients for the fluctuating components. Following the same line of reasoning, two statistical treatments (Equation (8): Time average of instantaneous terms; Equation (9): An approximation based on previously averaged terms) will be compared and plotted for the mean dissipation rate of fluctuant kinetic energy as in Figure 10: 
(a)

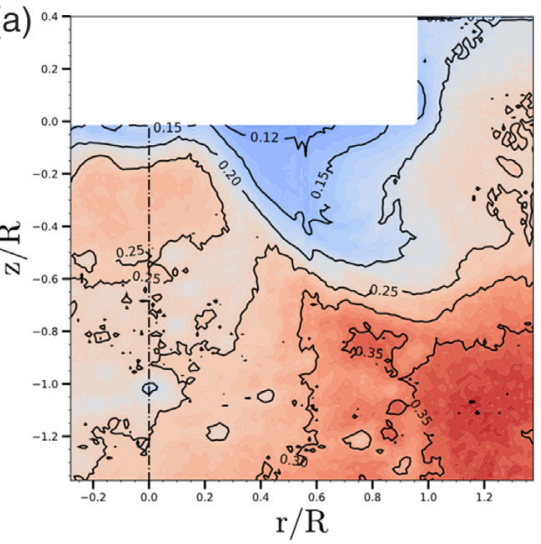

(c)

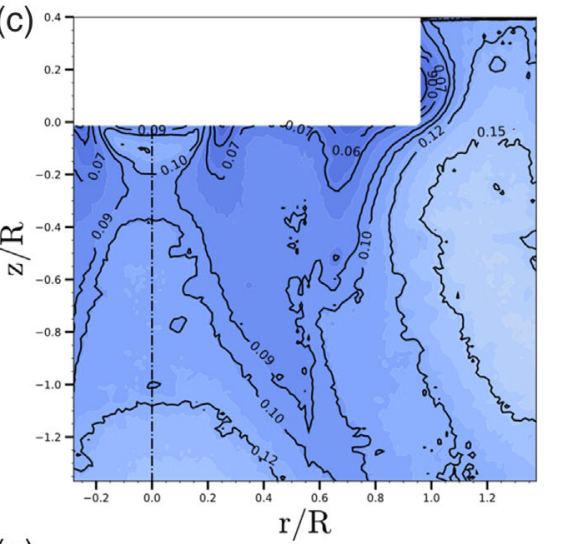

(e)

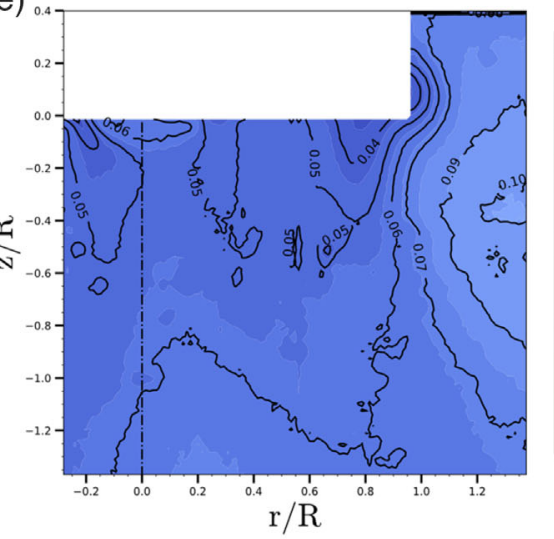

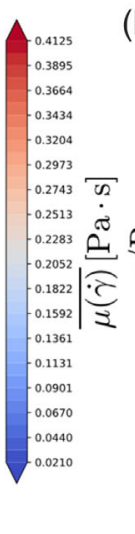

(b)

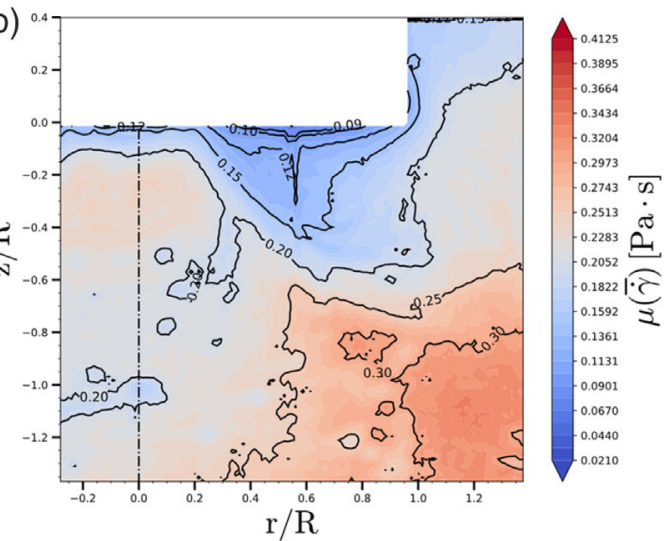

(d)
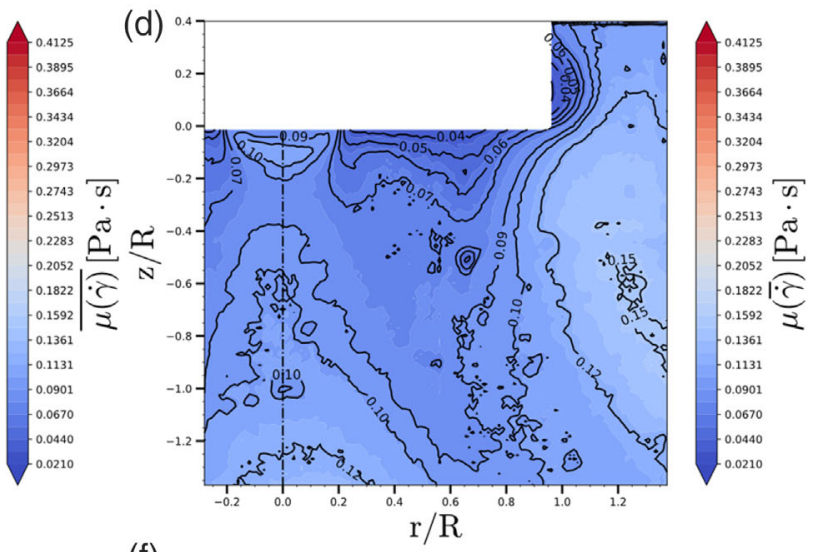

(f)

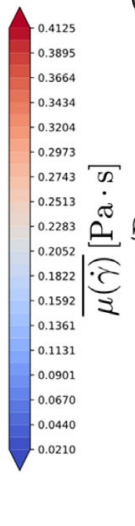

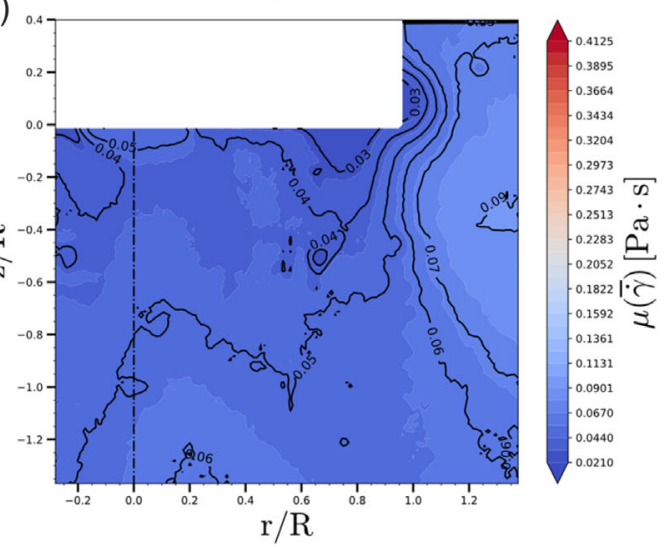

FIGURE 9 Logarithmically spaced contours of mean apparent viscosity calculated with (1) $\mu(\bar{\gamma})$ (a,c,e), and (2) $\mu\left(\dot{\gamma}_{\text {rms }}^{-}\right)$(b,d,f) for 100 (a,b); 250 (c, d); and $500 \mathrm{rpm}(\mathrm{e}, \mathrm{f})$ with at plane $\mathrm{YZ}(\mathrm{X}=0 \mathrm{~mm})$ [Color figure can be viewed at wileyonlinelibrary.com]

$$
\begin{gathered}
\varepsilon_{\text {fluc }}=\frac{\mu(\dot{\gamma})^{-}}{\rho} \dot{\gamma}_{\text {fluc }}{ }^{2} \\
\varepsilon_{\text {fluc,rec }}^{-}=\frac{\mu(\overline{\dot{\gamma}})}{\rho} \dot{\gamma}_{\text {fluc }}^{-} 2
\end{gathered}
$$

From Figure 10, a couple of observations can be made. The spatial distribution of the dissipation rate is different for all rotational speeds, being the maximum values located near the tip of the impeller and in the impeller discharge stream. As expected, the maximum value of $\varepsilon_{\overline{f l u c}}$ decreases as a function of rotational speed, but decays quickly away from the impeller. Additionally, at $500 \mathrm{rpm}$, the region around the rotational axis exhibits higher dissipation rates than the bulk zone.
This might be a consequence of the high local production of fluctuant kinetic energy close to the impeller, which results in peaks of fluctuant kinetic energy close to the impeller. When comparing results between Equations (8) and (9), it is obvious that the second method tends to overestimate its value especially in regions far from the impeller.

In Figure 11, it is seen that the magnitude of the peak is roughly the same order of magnitude than both literature references, being $\varepsilon_{\text {fluc }}$ much lower than in Rushton turbines. ${ }^{14,27}$ Additionally, the evolution of the radial profiles as a function of depth indicates the quick decay of the single peak towards a radial bulk uniform dissipation. It is interesting to compare the profiles with the volume averaged dissipation rate of kinetic energy $\langle\varepsilon\rangle$ at $500 \mathrm{rpm}$. Since it was not measured, for 

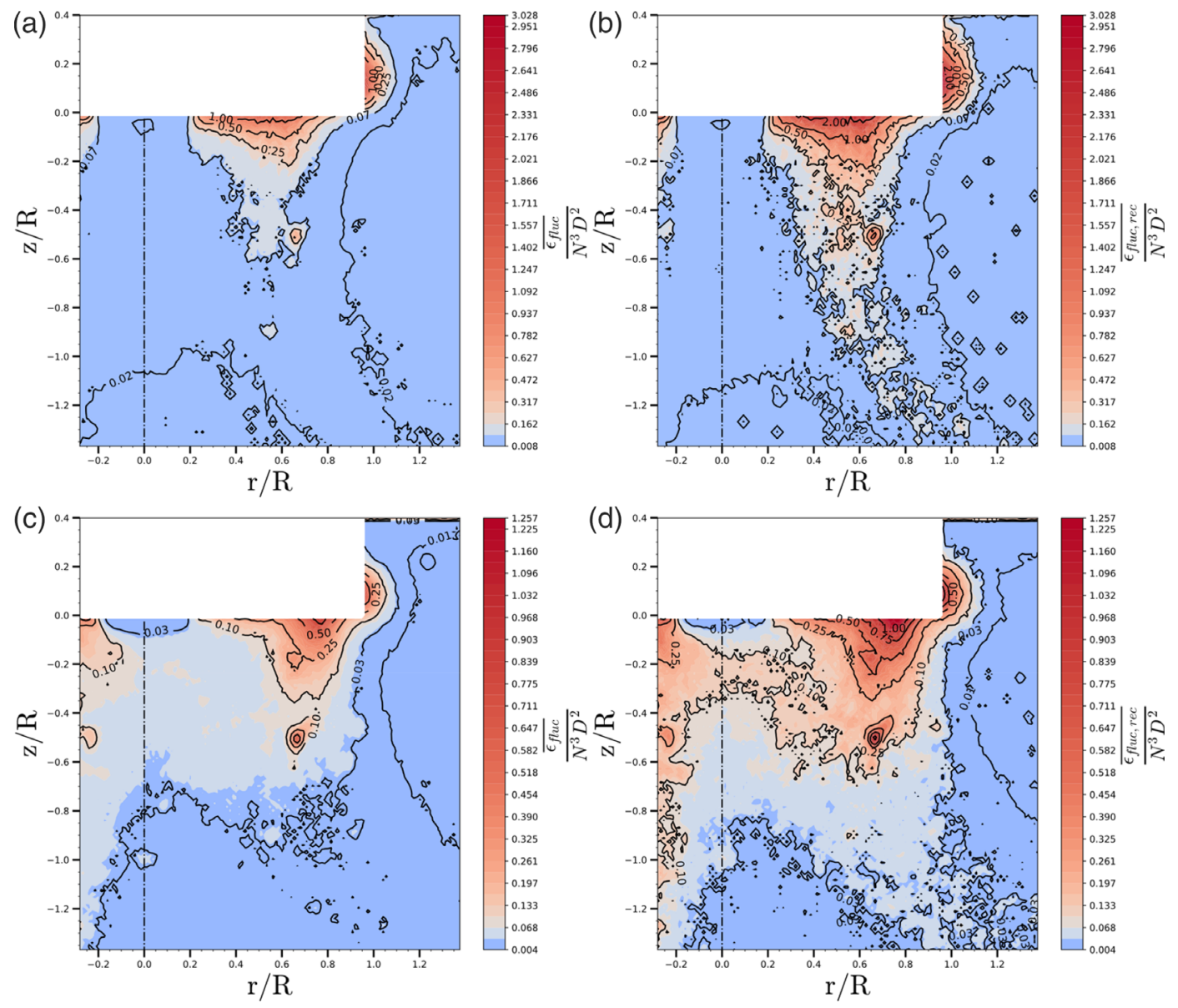

FIG URE 10 Contour plots of normalized averaged dissipation rate of fluctuant kinetic energy calculated with (1) $\varepsilon_{f l u c}(a, c)$, and (2) $\varepsilon_{f l u c} \bar{c}$ rec $(\mathrm{b}, \mathrm{d})$ for $250(a, b)$ and $500 \mathrm{rpm}(c, d)$ in plane $Y Z(X=0 \mathrm{~mm})$ [Color figure can be viewed at wileyonlinelibrary.com]

estimation purposes it will be assumed that the power number is constant for this impeller at this rotational speed using Equation (10) $\left(N_{p}=0.3,{ }^{2,21,47}\right)$ :

$$
\langle\varepsilon\rangle=\frac{P}{\rho}=\frac{N_{p} N^{3} D^{5}}{V}=0.184 \mathrm{~m}^{2} / \mathrm{s}^{3} ; \frac{\langle\varepsilon\rangle}{N^{3} D^{2}}=0.014
$$

As it can be noted, the local values exceed $\langle\varepsilon\rangle$ at the core of the jet by at least one order of magnitude but approaching its value in the bulk region.

\section{8 | Turbulent length scales}

After estimating the local dissipation rate of fluctuant kinetic energy, it is then possible to estimate the spatial distribution of two characteristic turbulent lengths (Equation (11)) named the Kolmogorov scale ( $\eta$ ), and the Taylor microscale $\left(\lambda_{\mathrm{T}}\right)$ :

$$
\bar{\eta}=\overline{\left(\frac{(\mu / \rho)^{3}}{\varepsilon^{\prime}}\right)^{1 / 4} ; \overline{\lambda_{\mathrm{T}}}}=\overline{\left(\frac{10 \nu K^{\prime}}{\varepsilon^{\prime}}\right)^{1 / 2}}
$$

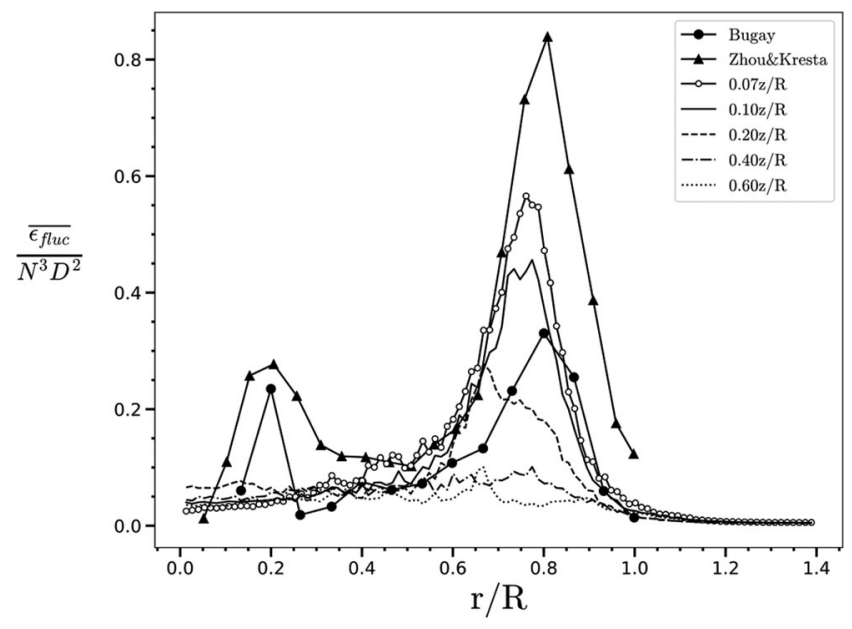

FIGURE 11 Normalized average dissipation rate of fluctuant kinetic energy $\left(\varepsilon_{\overline{f l u c}} /\left(N^{3} D^{2}\right)\right)$ profiles for $500 \mathrm{rpm}$ at $5,7.5,15,30$, and $45 \mathrm{~mm}(Z=-0.07,-0.10,-0.2,-0.4,-0.6 z / R)$ below the impeller using data from plane $Y Z(x=0 \mathrm{~mm})$. The data are compared to results from (Bugay et al. ${ }^{8} ; \mathrm{Re}=75,000$ ) and Zhou and Kresta ${ }^{6}$; $\operatorname{Re} \approx 93,000)$ using water at $200 \mathrm{rpm}$ at $5 \mathrm{~mm}(Z=-0.07 \mathrm{z} / R)$ below the impeller 
Although variables in Equation (11) are only strictly valid for fully turbulent conditions, it is still worth to obtain an estimation of their order of magnitude and spatial distribution. In particular, the PIV filter must be compared to the Taylor microscale to validate the kinetic energy estimations, and to the Kolmogorov scale to validate dissipation rate estimations. It is also noted that in Equation (11), turbulent components are strictly required so it is necessary to apply the POD decomposition. Since it is not clear (from Figure 7) on how many modes are necessary to describe organized motion, a conservative approach is taken and only Modes 2-3 are selected. Modes 2-3 constitute the most energetic modes since they account for $\sim 7.5 \%$ of $\bar{K}_{\text {TOT }}$ for 250 and $500 \mathrm{rpm}$. Additionally, the PIV spatial filter is sufficiently small as to not filter the most important fluctuations in the determination of $\overline{K^{\prime}}$.

In Figure 12, the Kolmogorov scale $(\bar{\eta})$ ranges from 0.4 to $0.55 \mathrm{~mm}$ for 250 and $500 \mathrm{rpm}$ while the Taylor microscale $\left(\overline{\lambda_{\mathrm{T}}}\right)$ varies between 5 and $15 \mathrm{~mm}$ in most of the flow field considered below the impeller. Relating the turbulent scales to the PIV filter $\left(\bar{\eta} / \Delta_{\text {PIV }} \approx 0.5\right.$ and $\bar{\lambda}_{\mathrm{T}} / \Delta_{\mathrm{PIV}} \approx 1-15$ ), these values are overall higher than other previous studies were water was used as a fluid and other impellers were considered. ${ }^{8,25}$ This result is important since the PIV resolution ( $\left.\Delta_{\mathrm{PIV}}\right)$ for all cases is considered sufficient ${ }^{48}$ to capture the most important energy fluctuations in the flow by not filtering them. This can be explained by relating $\bar{\eta}$ with the smallest turbulent scales that dissipate energy, and $\overline{\lambda_{\mathrm{T}}}$ with the minimum eddy length that significantly contributes to the turbulent kinetic energy. ${ }^{46}$

\section{9 $\quad$ Turbulent Reynolds number}

The local turbulent Reynolds number ( $\mathrm{Re}_{\mathrm{L}}$, Equation (12)) is defined based on dimensional analysis by calculating representative variables for the large-scale turbulence structures using local flow variables. ${ }^{43}$ The objective is to quantify the ratio of a "turbulent viscosity" over the apparent fluid viscosity:

$$
\operatorname{Re}_{\mathrm{L}}=\frac{\mu_{\mathrm{\top}}}{C_{\mu} \mu}=\frac{\rho \mathrm{v} \Lambda}{\mu}=\frac{\rho K \prime^{2}}{\mu \varepsilon^{\prime}}
$$

where $C_{\mu} \approx 0.09$ is an empirical constant, ${ }^{43}$ and $v$ and $\Lambda$ are characteristic velocity and length scales of the large-scale energy-containing turbulence structures.

Figure 13 reveals that a $2 \mathrm{D}$ estimation of $\mathrm{Re}_{\mathrm{L}}$ yields slightly different results for 250 and $500 \mathrm{rpm}$. Recall that in strict turbulent flow $\mathrm{Re}_{\mathrm{L}}>150$, so that approximately the ratio of turbulent viscosity and apparent fluid viscosity is $\frac{\mu_{\mathrm{T}}}{\mu}>15 .{ }^{48}$ When comparing $\operatorname{Re}_{\mathrm{L}}$ between the rotational speeds in Figure 13, $500 \mathrm{rpm}$ does achieve high levels within the downward axial jet and around the rotational (a)

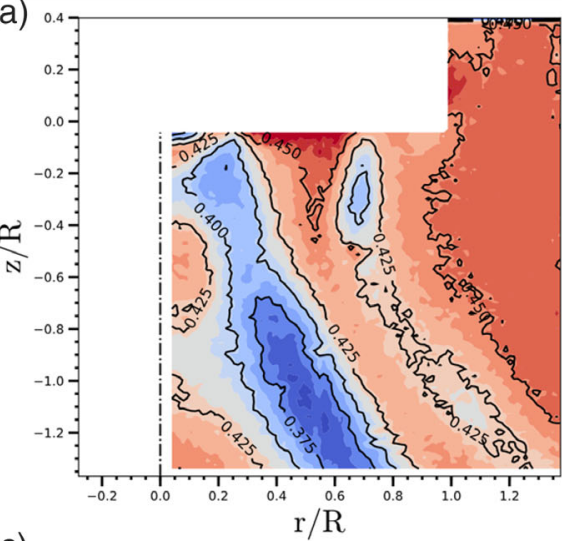

(c)

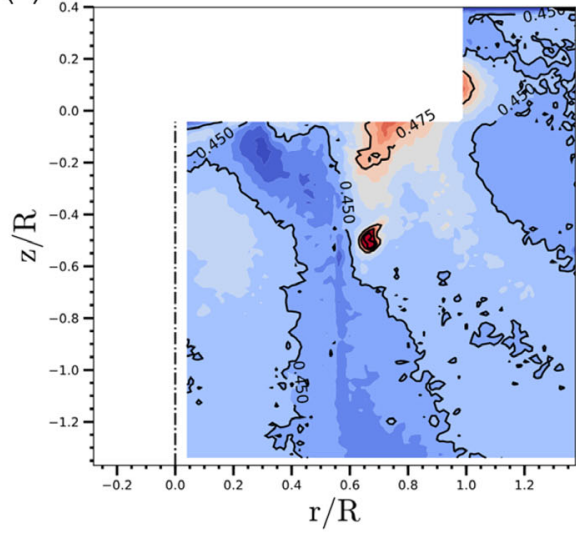

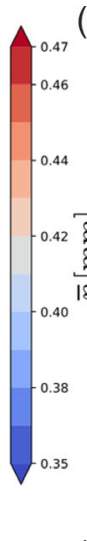

(b)

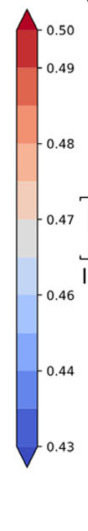

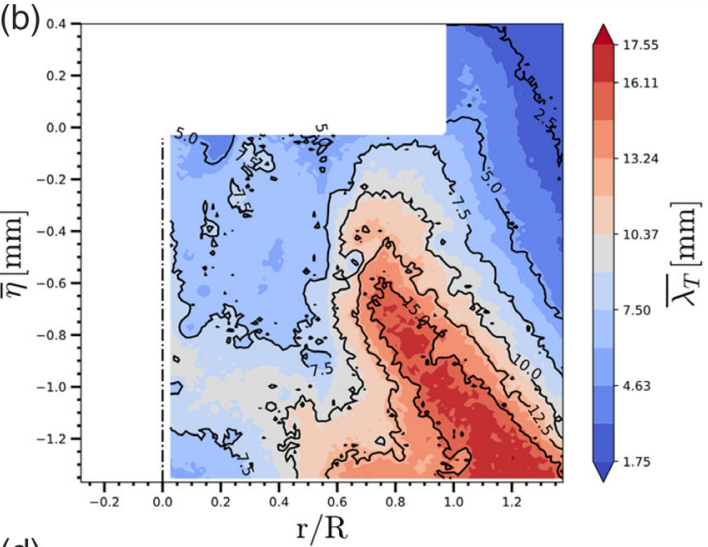

(d)

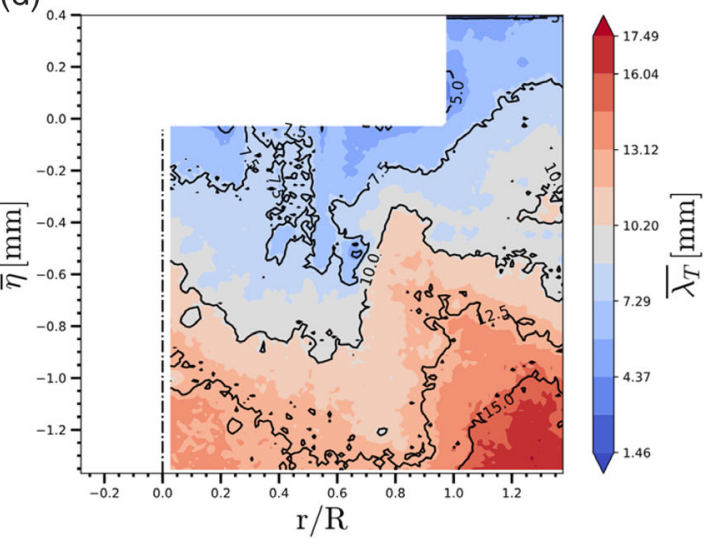

FIGURE 12 Contour plots of (1) Kolmogorov turbulent scale $[\bar{\eta}, a, c]$, (2) Taylor microscale $[\overline{\bar{T}}, \mathrm{~b}, \mathrm{~d}]$ for 250 (a,b), and $500 \mathrm{rpm}(\mathrm{c}, \mathrm{d})$ in plane YZ $(x=0 \mathrm{~mm})$ [Color figure can be viewed at wileyonlinelibrary.com] 
axis. On the other hand, lower levels are achieved at $250 \mathrm{rpm}$ with $\frac{\mu_{\mathrm{T}}}{\mu}=1$ within the boundaries of the downward axial jet, invalidating the turbulent viscosity concept. The turbulent viscosity hypothesis might seem to be strictly valid at most for the $500 \mathrm{rpm}$ case and only in the region studied. In both cases, the progressive turbulence damping imposed by the increasing viscosity of the fluid may seem to be the cause of such heterogeneity in $\mathrm{Re}_{\mathrm{L}}$. Recall that turbulence levels are related with the intensity of turbulence (in terms of turbulent kinetic energy), whereas turbulent viscosity is a measure of macromixing (since it contains an estimation of an integral length scale times the square root of turbulent kinetic energy).

\subsection{0 | Estimation of Reynolds number}

The shear rate is an important parameter because it influences the local material properties (viscosity) for non-Newtonian fluids. This is thought to be a consequence of the complex interaction between the swollen polymeric Carbopol molecules in water, ${ }^{49}$ which results in different parcels of fluids experiences different shear stresses. Therefore, the calculation of a global Reynolds (Re) number in nonNewtonian fluids is open for discussion since there is a wide range of scales that can be selected. ${ }^{14,50}$ In this work, the length and velocity scales were selected to be the impeller diameter and the tip velocity $\left(U_{\text {tip }} / \pi\right)$ so the Reynolds number (Equation (13)) can be defined with the HB rheological model (Equation (1)) as:

$$
\operatorname{Re}=\frac{\rho N D^{2}}{\mu}=\frac{\rho N D^{2}}{\frac{\tau_{o}}{\dot{\gamma}}+K \dot{\gamma}^{n-1}}
$$

where $\rho\left(\mathrm{kg} / \mathrm{m}^{3}\right)$ is the fluid density, $N\left(\mathrm{~s}^{-1}\right)$ is the impeller's rotational speed, and $D(m)$ is the impeller diameter.

Hence, in order to calculate the Reynolds number, it is necessary to establish a volume average shear rate of the system which, in turn, is representative of the viscosity of the system. This raises some important questions regarding the generality and applicability of the Reynolds number in non-Newtonian fluids since multiple viscosities can be selected. Although there are other approaches in literature to obtain the shear rate, ${ }^{9,51}$ traditionally the Metzner-Otto $\left(\mathrm{MO}^{52}\right.$; Equation (14)) approach is used to obtain a representative average shear rate for each type of impeller for non-Newtonian fluids.

$$
\dot{\gamma}_{\mathrm{MO}} \approx k_{\mathrm{MO}} \mathrm{N}
$$

where $\dot{\gamma}_{\mathrm{MO}}\left[\mathrm{s}^{-1}\right]$ is the representative average shear rate using the $\mathrm{MO}$ approach, and $k_{\mathrm{MO}}(-)$ is the MO proportionality constant for $A 310\left(k_{M O}=3.42^{2}\right)$.

However, there are important caveats when using Equation (14). First, $k_{\mathrm{MO}}$ has been shown to vary as a function of the flow regime. Second, there is no general and clear physical interpretation of $\dot{\gamma}_{\mathrm{MO}}$ for non-Newtonian fluids. Third, the calculation of $\dot{\gamma}_{\text {MO }}{ }^{2,9}$ usually involves the use of mean velocity gradients $\left(\bar{\gamma}_{\text {mean }}\right)$, and not the RMS of the instantaneous shear rates. Despite this, it is still possible to relate both (Equation (16)) by assuming equilibrium between (a)
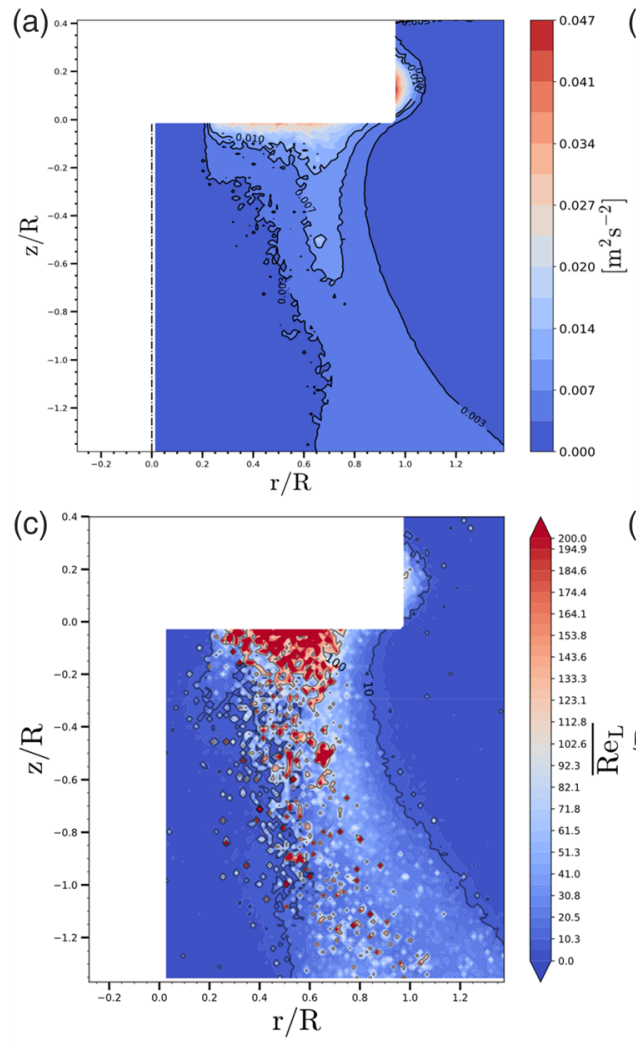

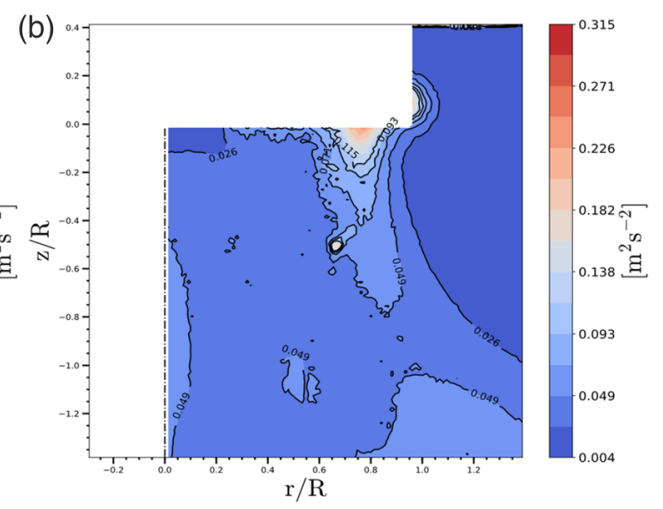

(d)

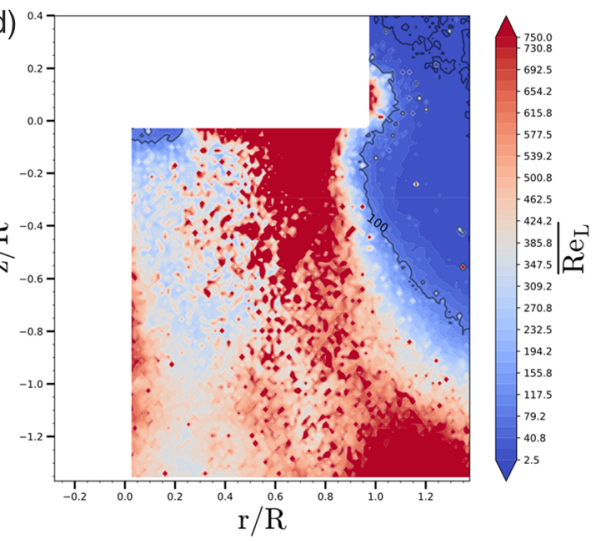

FIGURE 13 Contour plots of turbulent kinetic energy $\left(\overline{K^{\prime}}, a, b\right)$ and Reynolds turbulent number $\left(\operatorname{Re}_{\mathrm{L}}\right.$, c,d) for 250 (a,c), and $500 \mathrm{rpm}$ (b,d) using data from plane $Y Z(x=0 \mathrm{~mm})$. Contour lines are specified for $\mathrm{Re}_{\mathrm{L}}=10$ and 100 [Color figure can be viewed at wileyonlinelibrary.com] 
production and dissipation (Equation (15)) valid in fully turbulent flow ${ }^{43}$ using Equation (12):

$$
\begin{aligned}
& \text { Dissip. }(\overline{\mathrm{K}})=\overline{\varepsilon^{\prime}} \approx \operatorname{Prod} .\left(\bar{K}^{\prime}\right)=v_{t} \bar{\gamma}_{\text {mean }}^{2} \\
& \dot{\gamma}_{\text {rms }}^{-} \approx \sqrt{\frac{\varepsilon^{\prime}}{v}}=\sqrt{\frac{v_{t}}{v}} \dot{\gamma}_{\text {mean }}=\sqrt{C_{\mu} \operatorname{Re}_{\mathrm{L}}} \overline{\dot{\gamma}}_{\text {mean }}
\end{aligned}
$$

where $v_{t}=C_{\mu} \frac{{\frac{K^{\prime}}{}}_{\epsilon^{\prime}}{ }^{4}}{43}$ Equation (16) reveals that the difference in turbulent flow $\left(\operatorname{Re}_{\mathrm{L}} \approx 1,000\right)$ for the shear rate is one order of magnitude larger than the mean velocity gradient $\left(\dot{\gamma}_{\text {rms }}^{-} \approx \sqrt{0.09 \cdot 1,000} \approx 10 \overline{\dot{\gamma}}_{\text {mean }}\right)$, which is in accordance with theory from Reference 46. For lower Reynolds numbers $\left(\operatorname{Re}_{\mathrm{L}} \approx 160\right)$ and with laminar flow (in which Equations (15) and (16) may not be valid), the shear rate is comparable to the mean velocity gradient $\left(\dot{\gamma}_{\text {rms }}^{-} \approx 4 \overline{\dot{\gamma}}_{\text {mean }}\right)$. These have important implications since it is Equation (4) which governs viscosity and its use in the estimation of the Reynolds number. Finally, based on the analysis of Figure 9, local viscosity was shown to highly depend on the statistical treatment.

Figure 14 reveals that, for all rotational speeds, there is no direct correspondence between shear rate and apparent viscosity due to the nonlinearity of the HB model. More specifically, the shape of the distributions yields different characteristic peaks. This result indicates that Carbopol experience overall higher viscosities, and the use of a characteristic shear rate to obtain a representative viscosity is questionable. However, it is still interesting to understand the evolution of the characteristic histogram shear rates when plotted against the rotational speed to check for linear relations.

The first observation in Figure 15 is that when increasing $N$ (and thus $\mathrm{Re}$ ) the values of the $\mathrm{MO}$ correlation largely under predict the main characteristic values of the shear rate obtained from Figure 14. This is clearly seen by comparing the proportionality constants estimated from Figure 15. Interestingly, the MO correlation yields the highest agreement with the radial plane average $(r=[0-1 r / R])$ of $\overline{\dot{\gamma}}_{\text {mean }}$ reconstructed from mean velocity gradients at $-0.4 z / R$ below the impeller. Despite the few number of points considered, it is doubtful to find accurate and general non-Newtonian shear rate correlations that could be valid for the entire spectrum of flow regimes where linearity would hold. This is supported by experimental evidence ${ }^{53}$ that in turbulent regime $\dot{\gamma} \propto N^{3 /(n+1)}$ when using a power law model.

The difference in viscosities in Table 2 reveals that the discrepancy is higher the lower the rotational speed. In other words, the higher the turbulent regime, the smaller the differences in viscosity are. The different estimations of the non-Newtonian Reynolds number are also summarized in Table 2 based on Equation (13). (a)

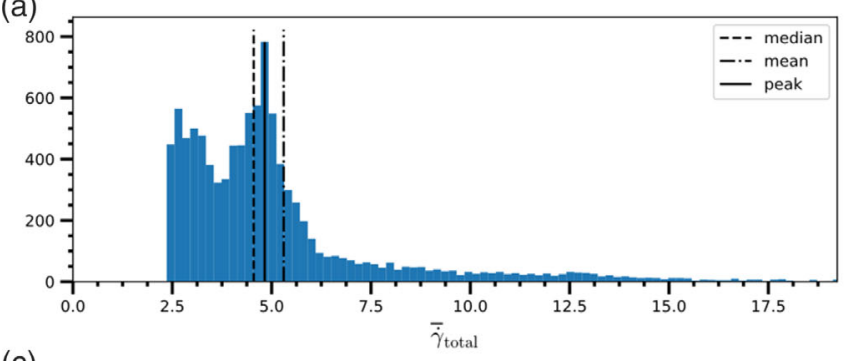

(c)

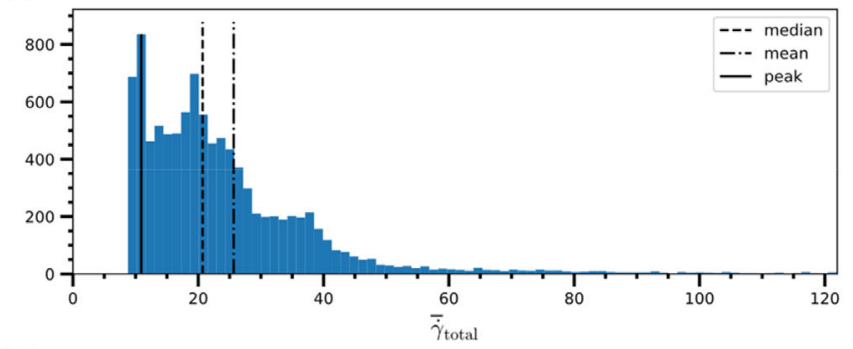

(e)

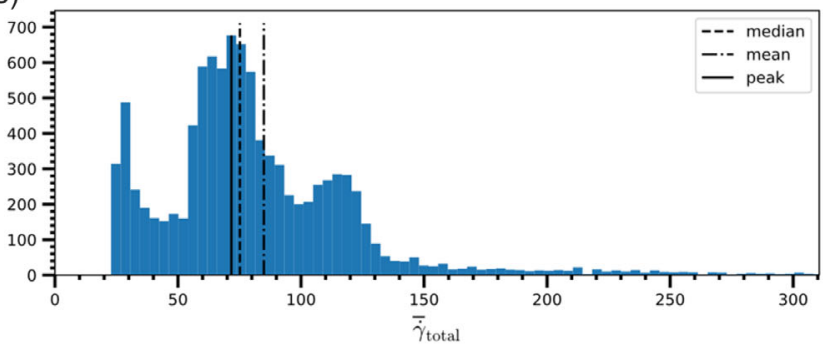

(b)

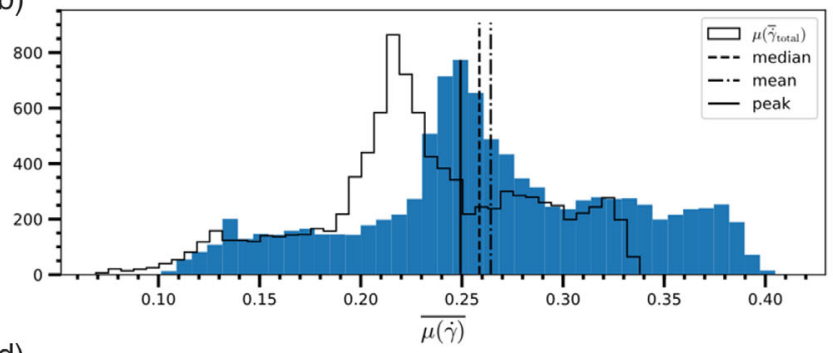

(d)

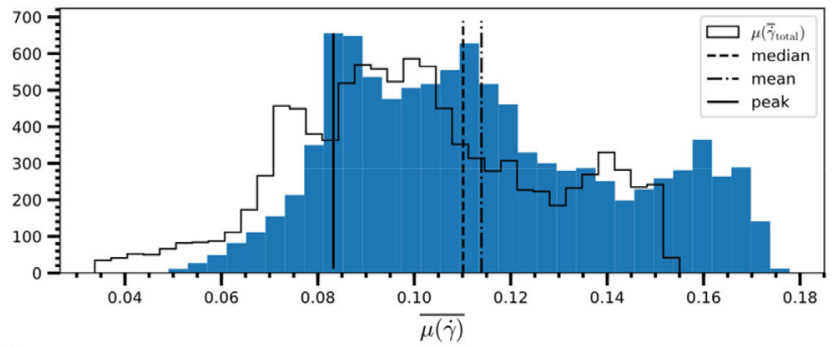

(f)

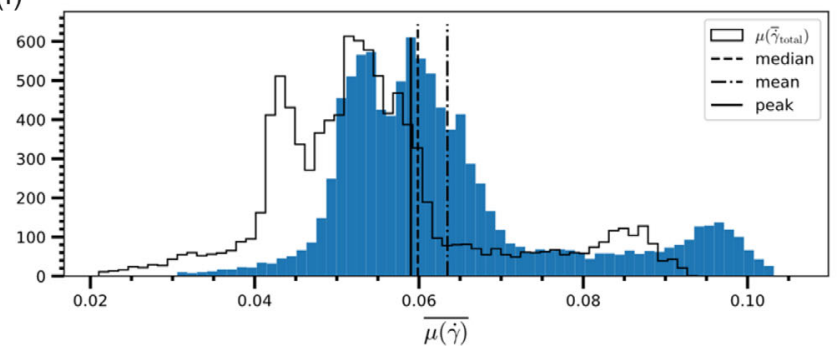

FIGURE 14 Histograms of the local averaged instantaneous total shear rate $\left(\dot{\gamma}_{\text {rms }}^{-}\right)$and instantaneous viscosity $(\mu(\bar{\gamma}))$ from plane $Y Z(x=0$ mm) for 100 (a,b); 250 (c,d); $500 \mathrm{rpm}(\mathrm{e}, \mathrm{f})$. A subset of $\mathrm{YZ}(x=0 \mathrm{~mm})$ planes data has been used with limits $(r, z=[0-1 r, z / R])[$ Color figure can be viewed at wileyonlinelibrary.com] 


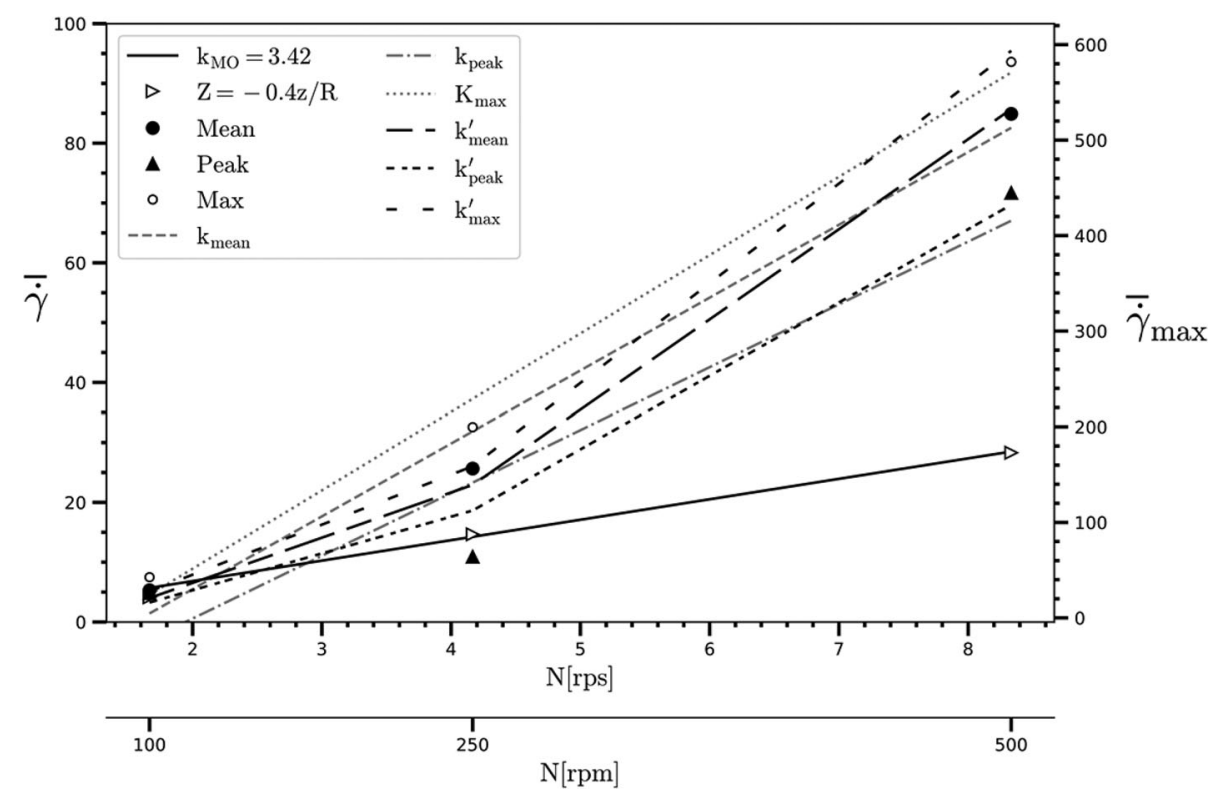

FIGURE 15 Evolution of the characteristic shear rates from Figure 14 against impeller's rotational speed. $\overline{\dot{\gamma}}=k \cdot N$ : $k_{\text {mean }}=12.17, k_{\text {peak }}=10.49, k_{\max }=82.01 ; \dot{\gamma}=k^{\prime} \cdot N^{\frac{3}{n+1}}: k_{\text {mean }}^{\prime}=1.51, k_{\text {peak }}^{\prime}=1.23, k_{\text {max }}^{\prime}=10.51$

\begin{tabular}{lllllllll}
$\mathrm{rpm}$ & $\dot{\gamma}_{\mathrm{MO}}$ & $\dot{\gamma}_{\mathrm{rms}}^{-}$ & $\mu_{\mathrm{MO}}$ & $\mu\left(\dot{\gamma}_{\mathrm{rms}}^{-}\right)$ & $\mu(\dot{\gamma})$ & $\operatorname{Re}_{\mu_{\mathrm{MO}}}$ & $\operatorname{Re}_{\mu\left(\dot{\gamma}_{\mathrm{rms}}^{-}\right)}$ & $\operatorname{Re}_{\mu(\overline{\dot{\gamma}})}$ \\
\hline 100 & 5.70 & 5.30 & 0.20 & 0.21 & 0.26 & 190 & 182 & 142 \\
\hline 250 & 14.25 & 25.65 & 0.12 & 0.09 & 0.11 & 785 & 1,061 & 823 \\
\hline 500 & 28.50 & 84.90 & 0.08 & 0.05 & 0.06 & 2,236 & 3,770 & 2,955 \\
\hline
\end{tabular}

TABLE 2 Characteristic shear rates and viscosities and associated nonNewtonian Reynolds number
Although there are some differences between Re values at the same rotational speed, it is possible to classify the flow at $100 \mathrm{rpm}$ as the beginning of the transitional regime, $250 \mathrm{rpm}$ would be in the transitional regime, and $500 \mathrm{rpm}$ would be close to turbulent conditions in the region considered. Based on this analysis, it is possible to conclude that the similarity in Reynolds numbers in Table 2 to estimate the flow regime permits the use of different definitions of shear rate and/or viscosity.

\section{4 | CONCLUSIONS}

In this work, an experimental mixing analysis using a non-Newtonian fluid stirred with an axial A310 impeller has been carried out. Local shear rates and local apparent viscosities as a function of different $N$ were determined (covering the onset of transitional, transitional, and turbulent regime). Based on this unique experimental dataset, it can be concluded that the flow field produced by this impeller is highly dependent on the shear thinning behavior of the fluid, as well as the rotational speed. Moreover, the spatial heterogeneity of shear rates and viscosities is greater when the rotational speed decreases. Additionally, the difference between $\dot{\gamma}_{\text {rms }}^{-}$(based on time-averaged instantaneous velocity gradients) and $\bar{\gamma}_{\text {mean }}$ (based on mean velocity gradients) is larger for higher rotational speeds. Interestingly, the computation of the time-averaged viscosity using two different statistical methods (rigorous vs. CFD approximation) revealed some notable differences. Multiple characteristic shear rates and viscosities can be selected below the impeller to fit different correlations. The traditional MO correlation is obtained when using only mean velocity gradients. Finally, the estimation of a generalized Reynolds number to characterize the flow regime has been performed using different characteristic viscosities. Despite the observed deviations, a correct order of magnitude estimation can be obtained for any system displaying this rheology. In this respect, the flow below the impeller at 100 and $250 \mathrm{rpm}$ could be classified in the transitional regime whereas $500 \mathrm{rpm}$ is close to achieve fully turbulent conditions. The use of a fluid proxy to simulate the rheological behavior of digested sludge has proven to be effective in building such dataset for future validation of CFD simulations representing fermenters and AD.

\section{ACKNOWLEDGMENTS}

The authors wish to acknowledge that this research has been funded by Ghent University (Belgium) through GOA Project BOF16/GOA/004. Additionally, the authors also would like to thank Jose Moreau and David Laupsien for the help received during the PIV experiments, and the University of Toulouse for the PIV equipment funding.

\section{NOTATION}

$\begin{array}{ll}\tau & \text { shear stress }(\mathrm{Pa}) \\ \tau_{\mathrm{O}} & \text { apparent yield stress }(\mathrm{Pa})\end{array}$


consistency index $\left(\mathrm{Pa} \cdot \mathrm{s}^{\mathrm{n}}\right)$

$\Lambda$

power index

magnitude of shear rate $\left(\mathrm{s}^{-1}\right)$

fluid density $\left(\mathrm{kg} / \mathrm{m}^{3}\right)$

apparent viscosity $(\mathrm{Pa} / \mathrm{s})$

kinematic viscosity $\left(\mathrm{m}^{2} / \mathrm{s}\right)$

tank volume (L)

baffle width $(\mathrm{m})$

diameter of the tank $(\mathrm{m})$

liquid height $(\mathrm{m})$

impeller diameter (m)

blade tip radius ( $\mathrm{m}$ )

impeller clearance $(\mathrm{m})$

rotational impeller speed $\left(\mathrm{min}^{-1}\right)$

velocity components in Cartesian frame $(\mathrm{m} / \mathrm{s})$

velocity components in cylindrical frame $(\mathrm{m} / \mathrm{s})$

PIV time interval (ms)

RMS of the 2D fluctuating velocity $(\mathrm{m} / \mathrm{s})$

impeller tip velocity $(\mathrm{m} / \mathrm{s})$

total number of PIV snapshots

number of POD modes

POD mode number

POD eigenvalue of Mode I

normalized POD eigenvalue of mode I

time averaged total kinetic $2 \mathrm{D} \mathrm{KE}\left(\mathrm{m}^{2} / \mathrm{s}^{2}\right)$

time averaged turbulent $2 \mathrm{D} \mathrm{KE}\left(\mathrm{m}^{2} / \mathrm{s}^{2}\right)$

time averaged RMS of the $2 \mathrm{D}$ shear rate $\left(\mathrm{s}^{-1}\right)$

maximum time averaged $2 \mathrm{D}$ shear rate $\left(\mathrm{s}^{-1}\right)$

time-averaged viscosity computed from instantaneous 2D shear rates $(\mathrm{Pa} / \mathrm{s})$

viscosity computed using time averaged RMS of $2 \mathrm{D}$ shear rate $(\mathrm{Pa} / \mathrm{s})$

instantaneous dissipation rate of total, fluctuant, and turbulent $\mathrm{KE}\left(\mathrm{m}^{2} / \mathrm{s}^{3}\right)$

time averaged dissipation rate of $\mathrm{KE}$

instantaneous velocity gradient of $i$ component $i$ in j direction $\left(s^{-1}\right)$

instantaneous total and fluctuating shear rate tensors $\left(\mathrm{s}^{-1}\right)$

mean shear rate tensor $\left(\mathrm{s}^{-1}\right)$

time averaged reconstruction of dissipation rate of fluctuant $\mathrm{KE}\left(\mathrm{m}^{2} / \mathrm{s}^{3}\right)$

Reynolds number

impeller Power number

volume averaged dissipation rate of $\mathrm{KE}\left(\mathrm{m}^{2} / \mathrm{s}^{3}\right)$

power dissipated by the fluid $\left(\mathrm{kg} \cdot \mathrm{m}^{-2} / \mathrm{s}^{3}\right)$

turbulent Reynolds number

turbulent viscosity $(\mathrm{Pa} / \mathrm{s})$

kinematic turbulent viscosity $\left(\mathrm{m}^{2} / \mathrm{s}\right)$

turbulent viscosity constant

characteristic velocity of the large-scale energycontaining turbulence structures $(\mathrm{m} / \mathrm{s})$ characteristic length of the large-scale energycontaining turbulence structures $(\mathrm{m})$

$\dot{\gamma}_{\text {MO }} \quad$ MO representative average shear rate $\left(\mathrm{s}^{-1}\right)$

kMO MO proportionality constant

$\mu_{\mathrm{MO}} \quad$ viscosity computed from $\mathrm{MO}$ correlation $(\mathrm{Pa} / \mathrm{s})$

$\overline{\dot{\gamma}}_{\text {mean }} \quad$ mean shear rate computed from mean velocity gradients $\left(s^{-1}\right)$

$k_{\text {mean, }} \quad$ proportional constants in shear rate versus

peak, $\max$ correlation

$k_{\text {mean, }}^{\prime} \quad$ proportional constants in shear rate versus $N^{\frac{3}{n+1}}$

peak, max

correlation

ORCID

David Fernandes del Pozo (D) https://orcid.org/0000-0002-8652-6825

Kevin M. Van Geem (D) https://orcid.org/0000-0003-4191-4960

\section{REFERENCES}

1. Paul LE, Victor AAO, Suzanne MK. Handbook of Industrial Mixing: Science and Practice. New York, NY: John Wiley and Sons; 2003.

2. Weetman RJ, Oldshue JY. Power, Flow, and Shear Characteristics of Mixing Impellers. In European Conference on Mixing. Pavia, Italy; 1988.

3. Benz GT. Consider hydrofoil impellers for laminar-flow Mixing. Chem Eng Prog. 2018;114(5):30-35.

4. Chapple D, Kresta SM. The effect of geometry on the stability of flow patterns in stirred tanks. Chem Eng Sci. 1994;49(21):3651-3660.

5. Mavros P, Baudou C. Quantification of the performance of agitators in stirred vessels: definition and use of an agitation index. Trans IChemE. 1997;75(8):737-745.

6. Zhou G, Kresta SM. Impact of tank geometry on the maximum turbulence energy dissipation rate for impellers. AIChE J. 1996;42(9): 2476-2490.

7. Zhou G, Kresta SM. Distribution of energy between convective and turbulent flow for three frequently used impellers. Trans Ind Chem Eng. 1996;74(3):379-389.

8. Bugay S, Escudie R, Line A. Experimental analysis of hydrodynamics in axially agitated tank. AIChE J. 2002;48(3):463-475

9. Wu J, Graham LJ, Mehidi NN. Estimation of agitator flow shear rate. AlChE J. 2006;52(7):2323-2332.

10. Murthy BN, Joshi JB. Assessment of standard k $-\varepsilon$, RSM and LES turbulence models in a baffled stirred vessel agitated by various impeller designs. Chem Eng Sci. 2008;63(22):5468-5495.

11. Montante G, Paglianti A. Fluid dynamics characterization of a stirred model bio-methanation digester. Chem Eng Res Des. 2014;3:38-47.

12. Saeed S, Ein-mozaffari F, Upreti SR. Using computational fluid dynamics to study the dynamic behavior of the continuous mixing of Herschel - Bulkley fluids. Ind Eng Chem Res. 2008;47:7465-7475.

13. Guntzburger Y, Fontaine A, Fradette L, Bertrand F. An experimental method to evaluate global pumping in a mixing system: application to the Maxblend ${ }^{\mathrm{TM}}$ for Newtonian and non-Newtonian fluids. Chem Eng J. 2013;214:394-406

14. Gabelle J, Morchain J, Anne-archard D, Augier F, Line A. Experimental determination of the shear rate in a stirred tank with a nonNewtonian fluid: Carbopol. AIChE J. 2013;59(6):2251-2266.

15. Story A, Jaworski Z. A new model of cavern diameter based on a validated CFD study on stirring of a highly shear-thinning fluid. Chem Pap. 2017;71:1255-1269.

16. Spicer PT, Keller W, Pratsinis S E. The effect of impeller type on floc size and structure during shear-induced flocculation. J Colloid Interface Sci. 1996;122:112-122. 
17. Bouyer D, Line A, Do-quang Z. Experimental analysis of floc size distribution under different hydrodynamics in a mixing tank. AIChE J. 2004;50(9):2064-2081.

18. Wu J, Graham L, Nguyen B, Mehidi MNN. Energy efficiency study on axial flow impellers. Chem Eng Process. 2006;45:625-632.

19. Coufort C, Dumas C, Bouyer D, Lin A. Analysis of floc size distributions in a mixing tank. Chem Eng Process. 2008;47:287-294.

20. Collignon M, Delafosse A, Crine $M$, Toye D. Axial impeller selection for anchorage dependent animal cell culture in stirred bioreactors: methodology based on the impeller comparison at just-suspended speed of rotation. Chem Eng Sci. 2010;65:5929-5941.

21. Machado MB, Kresta SM. The confined impeller stirred tank ( CIST ): a bench scale testing device for specification of local mixing conditions required in large scale vessels. Chem Eng Res Des. 2013;1:22092224.

22. Machado MB, Bittorf KJ, Roussinova VT, Kresta SM. Transition from turbulent to transitional flow in the top half of a stirred tank. Chem Eng Sci. 2013;98:218-230.

23. Lane GL. Improving the accuracy of CFD predictions of turbulence in a tank stirred by a hydrofoil impeller. Chem Eng Sci. 2017;169: 188-211.

24. Ducoste JJ, Clark MM, Weetman RJ. Turbulence in flocculators: effects of tank size and impeller type. AIChE J. 1997;43(2):328-338.

25. Escudie R, Line A. Experimental analysis of hydrodynamics in a radially agitated tank. AIChE J. 2003;49(3):585-603.

26. Baldi S, Yianneskis M. On the quantification of energy dissipation in the impeller stream of a stirred vessel from uctuating velocity gradient measurements. Chem Eng Sci. 2004;59:2659-2671.

27. Ducci A, Yianneskis M. Direct determination of energy dissipation in stirred vessels with two-point LDA. AIChE J. 2005;51(8):2133-2149.

28. Batstone DJ, Puyol D, Rodríguez J, Flores-Alsina X. Mathematical modelling of anaerobic digestion processes: applications and future needs. Rev Env Sci Biotechnol. 2015;14:595-613.

29. Samstag RW, Ducoste JJ, Griborio A, et al. CFD for wastewater treatment: an overview. Water Sci Technol. 2016;74(3):549-563.

30. Wicklein E, Batstone DJ, Ducoste J, Laurent J, Potier O, Nopens I. Good modelling practice in applying computational fluid dynamics for WWTP modelling. Water Sci Technol. 2016;73(5):969-982.

31. Karim K, Varma R, Vesvikar M. Flow pattern visualization of a simulated digester. Water Res. 2004;38:3659-3670.

32. Hoffmann RA, Garcia ML, Veskivar M, Karim K, Al-dahhan MH, Angenent LT. Effect of shear on performance and microbial ecology of continuously stirred anaerobic digesters treating animal manure. Biotechnol Bioeng. 2008;100(1):38-48.

33. Sindall RC, Dapelo D, Leadbeater T, Bridgeman J. Positron emission particle tracking (PEPT): a novel approach to flow visualisation in labscale anaerobic digesters. Flow Meas Instrum. 2017;54:250-264. https://doi.org/10.1016/j.flowmeasinst.2017.02.009.

34. Cheng S, Nicky L, Paul E, Baudez SJ. Mixing characteristics of sludge simulant in a model anaerobic digester. Bioprocess Biosyst Eng. 2016; 39(3):473-483.

35. Dapelo D, Alberini F, Bridgeman J. Euler-Lagrange CFD modelling of unconfined gas mixing in anaerobic digestion. Water Res. 2015;85: 497-511.

36. Eshtiaghi N, Yap SD, Markis F, Baudez JC, Slatter P. Clear model fluids to emulate the rheological properties of thickened digested sludge. Water Res. 2012;46(9):3014-3022.
37. Eshtiaghi N, Markis F, Dong S, Baudez J, Slatter P. Rheological characterisation of municipal sludge: a review. Water Res. 2013;7:5493-5510.

38. Roberts GP, Barnes HA. New measurements of the flow-curves for Carbopol dispersions without slip artefacts. Rheol Acta. 2001;40(5):499-503.

39. Divoux T, Barentin C, Manneville S. From stress-induced fluidization processes to Herschel-Bulkley behavior in simple yield stress fluids. Soft Matter. 2011;7:8409-8418.

40. Di GE, Corbi F, Funiciello F, et al. Tectonophysics characterization of Carbopol ${ }^{\circledR}$ hydrogel rheology for experimental tectonics and geodynamics. Tectonophysics. 2015;642:29-45.

41. Arratia PE, Arratia PE, Kukura J, Lacombe J, Muzzio FJ. Mixing of shear-thinning fluids with yield stress in stirred tanks mixing of shearthinning fluids with yield stress. AIChE J. 2006;52(7):2310-2322.

42. Moreau J, Line A. Proper orthogonal decomposition for the study of hydrodynamics in a mixing tank. AlChE J. 2006;52(7):2651-2655.

43. Pope SB. Turbulent flows. Cambridge, UK: Cambridge University Press; 2000.

44. Van Oudheusden BW, Scarano F, van Hinsberg NP, Watt DW. Phase-resolved characterization of vortex shedding in the near wake of a square-section cylinder at incidence. Exp Fluids. 2005;39:86-98.

45. Knight B, Sirovich L. Kolmogorov inertial range for inhomogeneous turbulent flows. Phys Rev Lett. 1990;65(11):1356-1359.

46. Tennekes H, Lumley JL. A First Course in Turbulence; Cambridge, MA: MIT Press, 1972.

47. Wu J, Pullum L. Performance analysis of axial-flow mixing impellers. AIChE J. 2000;46(3):489-498.

48. Chassaing P. Turbulence en Mécanique Des Fluides. Toulouse: Cépaduès Édition; 2000.

49. Piau JM. Carbopol gels: elastoviscoplastic and slippery glasses made of individual swollen sponges. Meso- and macroscopic properties, constitutive equations and scaling laws. J Non-Newton Fluid Mech. 2007;144(1):1-29.

50. Venneker BCH, Derksen JJ, Van den Akker HEA. Turbulent flow of shear-thinning liquids in stirred tanks-the effects of Reynolds number and flow index. Chem Eng Res Des. 2010;88(7):827-843.

51. Grenville RK, Giacomelli JJ, Padron G, Brown DAR. Mixing: impeller performance in stirred tanks. Chem Eng. 2017;124(8):42-51.

52. Metzner A, Otto RE. Agitation of non-Newtonian fluids. AlChE J. 1957;3(1):3-10.

53. Sanchez Perez JA, Rodriguez Porcel EM, Casas Lopez JL, Fernandez Sevilla JM, Chisti Y. Shear rate in stirred tank and bubble column bioreactors. Chem Eng J. 2006;124(1-3):1-5.

\section{SUPPORTING INFORMATION}

Additional supporting information may be found online in the Supporting Information section at the end of this article.

How to cite this article: Fernandes del Pozo D, Liné A, Van Geem KM, Le Men C, Nopens I. Hydrodynamic analysis of an axial impeller in a non-Newtonian fluid through particle image velocimetry. AIChE J. 2020;66:e16939. https://doi.org/10. 1002/aic.16939 